
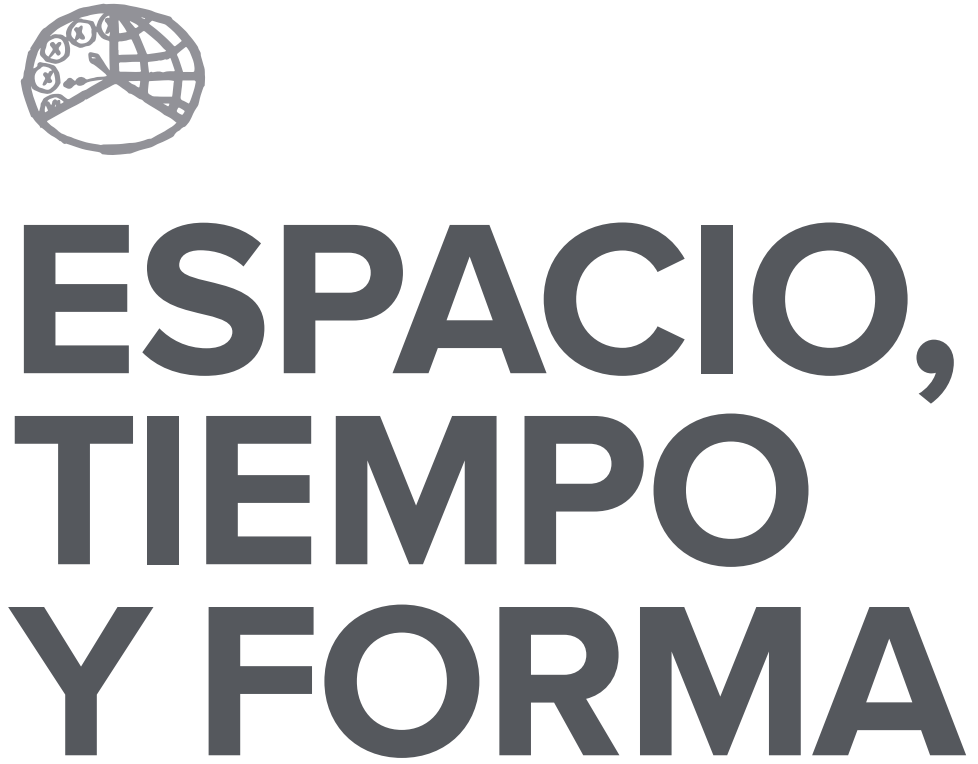

AÑO 2021

ISSN 0214-9745

E-ISSN 2340-1362

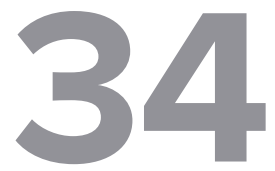

SERIE III HISTORIA MEDIEVAL

REVISTA DE LA FACULTAD DE GEOGRAFÍA E HISTORIA

VOLUMEN I 


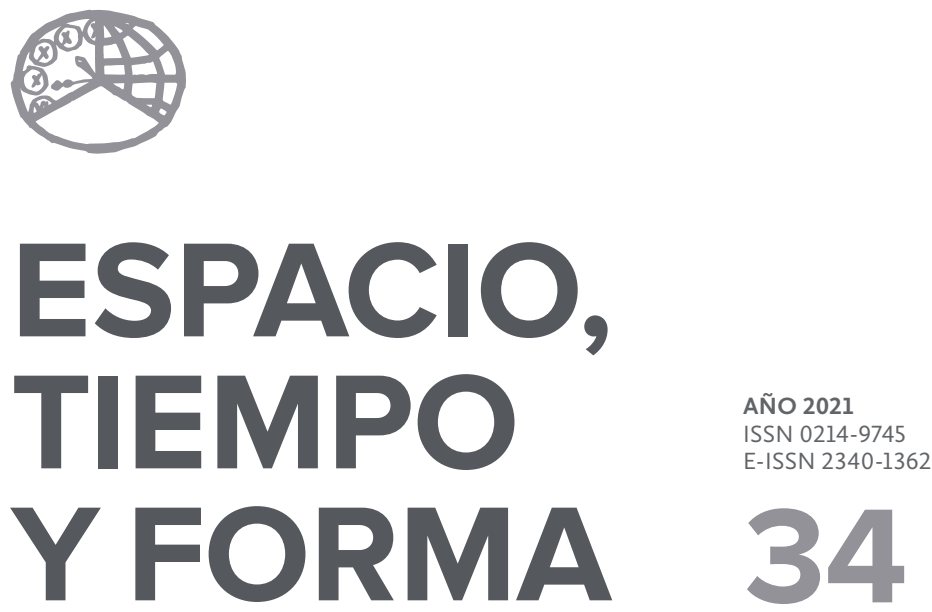

SERIE III HISTORIA MEDIEVAL

REVISTA DE LA FACULTAD DE GEOGRAFÍA E HISTORIA

VOLUMEN I

http://dx.doi.org/10.5944/etfiii.34.2021

\section{UกED}

UNIVERSIDAD NACIONAL DE EDUCACIÓN A DISTANCIA 
La revista Espacio, Tiempo y Forma (siglas recomendadas: ETF),

de la Facultad de Geografía e Historia de la UNED, que inició su publicación el año 1988, está organizada de la siguiente forma:

$$
\begin{aligned}
& \text { SERIE I - Prehistoria y Arqueología } \\
& \text { SERIE II - Historia Antigua } \\
& \text { SERIE III - Historia Medieval } \\
& \text { SERIE IV - Historia Moderna } \\
& \text { SERIE V - Historia Contemporánea } \\
& \text { SERIE VI - Geografía } \\
& \text { SERIE VII - Historia del Arte }
\end{aligned}
$$

Excepcionalmente, algunos volúmenes del año 1988 atienden a la siguiente numeración:
N. ${ }^{\circ} 1 \quad-$ Historia Contemporánea
N. ${ }^{\circ} 2-$ Historia del Arte
N. ${ }^{\circ} 3-$ Geografía
N. ${ }^{\circ} 4 \quad-$ Historia Moderna

ETF no se solidariza necesariamente con las opiniones expresadas por los autores.

UNIVERSIDAD NACIONAL DE EDUCACIÓN A DISTANCIA

Madrid, 2021

SERIE III - HISTORIA MEDIEVAL N. ${ }^{\circ} 34,2021$

ISSN 0214-9745 · E-ISSN 2340-1362

DEPÓSITO LEGAL M-21037-1988

URL: ETF III · HISTORIA MEDIEVAL · http://revistas.uned.es/index.php/ETFIII

DISEÑO Y COMPOSICIÓN

Carmen Chincoa Gallardo · http://www.laurisilva.net/cch

Impreso en España $\cdot$ Printed in Spain 
Espacio, Tiempo y Forma. Serie III. Historia Medieval es la revista científica fundada en I988 que publica el Departamento de Historia Medieval y Ciencias y Técnicas Historiográficas de la Facultad de Geografía e Historia de la UNED. Está dedicada al estudio de la Historia Medieval y acoge trabajos inéditos de investigación, en especial artículos que constituyan una aportación novedosa, que enriquezcan el campo de estudio que abordan y que ofrezcan una perspectiva de análisis crítico. Va dirigida preferentemente a la comunidad científica y universitaria, tanto nacional como internacional, así como a todos los profesionales de la Historia Medieval en general. Su periodicidad es anual y se somete al sistema de revisión por pares ciegos. La revista facilita el acceso sin restricciones a todo su contenido desde el momento de su publicación en edición electrónica. Espacio, Tiempo y Forma. Serie III. Historia Medieval se publica en formato electrónico y en papel.
Espacio, Tiempo y Forma. Serie III. Historia Medieval (Space, Time and Form. Series III. Medieval History) is a peerreviewed academic journal founded in I988 and published by the Department of Medieval History and Historiographical Sciences and Techniques at the Faculty of Geography and History, UNED. It is devoted to the study of Medieval History and is addressed to the Spanish and international scholarly community, as well as to professionals in the field of Medieval History. The journal welcomes previously unpublished articles, particularly works that provide an innovative approach, contribute to its field of research and offer a critical analysis. It is published annually. The journal provides complete open access to its content available online upon publication. Espacio, Tiempo y Forma. Serie III. Historia Medieval is published online and in print and is indexed in the databases and directories enumerated below.

Espacio, Tiempo y Forma. Serie III. Historia Medieval está registrada e indexada en Repertorios Bibliográficos y Bases de Datos nacionales e internacionales, como recomiendan los criterios de la Comisión Nacional Evaluadora de la Actividad Investigadora: LATINDEX, DICE, ISOC (CINDOC), RESH, INRECH, Dialnet, e-spacio UNED, CIRC 2.o (20I6), MIAR, FRANCIS, PIO, Ulrich's, SUDOC, ZDB, ERIH (ESF), REDIB, Repertorio de Medievalismo Hispánico, Directory of Open Access Journals (DOAJ), Emerging Sources Citation Index (ESCI), SCOPUS. La revista ha obtenido el Sello de Calidad de la FECYT (2018).

\section{EQUIPO EDITORIAL}

Edita: Departamento de Historia Medieval y Ciencias y Técnicas Historiográficas, Universidad Nacional de Educación a Distancia

Director del Consejo de Redacción: Enrique Cantera Montenegro (UNED)

Editores: Enrique Cantera Montenegro (UNED), Carlos Barquero Goñi (UNED) 
CONSEJO DE REDACCIÓN

Cristina Álvarez Millán

Departamento de Historia Medieval y Ciencias y Técnicas Historiográficas, UNED

Ana Arranz Guzmán

Universidad Complutense de Madrid

Carlos de Ayala Martínez

Universidad Autónoma de Madrid

Carlos Barquero Goñi

Departamento de Historia Medieval y Ciencias y Técnicas Historiográficas, UNED

Enrique Cantera Montenegro

Departamento de Historia Medieval y Ciencias y Técnicas Historiográficas, UNED

Ana Echevarría Arsuaga

Departamento de Historia Medieval y Ciencias y Técnicas Historiográficas, UNED

José María de Francisco Olmos

Universidad Complutense de Madrid

María Jesús Fuente Pérez

Universidad Carlos III de Madrid

Manuel Fernando Ladero Quesada

Departamento de Historia Medieval y Ciencias y Técnicas Historiográficas, UNED

Paulina López Pita

Departamento de Historia Medieval y Ciencias y Técnicas Historiográficas, UNED

José Miguel López Villalba

Departamento de Historia Medieval y Ciencias y Técnicas Historiográficas, UNED

José María Monsalvo Antón

Universidad de Salamanca

Isabel Montes Romero-Camacho

Universidad de Sevilla

Gonzalo Viñuales Ferreiro

Universidad Rey Juan Carlos

COMITÉ CIENTÍFICO

Vicente Ángel Álvarez Palenzuela

Universidad Autónoma de Madrid

Daniel Baloup

Université de Toulouse-Le Mirail

Vicente García Lobo

Universidad de León

María Estela González de Fauve

Universidad de Buenos Aires · Fundación para la Historia de España

César González Mínguez

Universidad del País Vasco 
Nikolas Jaspert

Ruhr-Universität Bochum, Alemania

DIRECTORA DE ETF SERIES I-VII

Yayo Aznar Almazán

Decana Facultad de Geografía e Historia, UNED

SECRETARIO DE ETF SERIES I-VII

Julio Fernández Portela

Departamento de Geografía, UNED

GESTORA PLATAFORMA OJS

Carmen Chincoa Gallardo

COMITÉ EDITORIAL DE ETF SERIES I-VII

Carlos Barquero Goñi, Departamento de Historia Medieval y Ciencias y Técnicas Historiográficas, UNED; Enrique Cantera Montenegro, Departamento de Historia Medieval y Ciencias y Técnicas Historiográficas, Uned; Pilar Díez del Corral Corredoira, Departamento de Historia del Arte, UneD; Carmen Guiral Pelegrín, Departamento de Prehistoria y Arqueología (Arqueología), Uned; Patricia Hevia Gómez, Departamento de Prehistoria y Arqueología (Arqueología), unED; Luiza lordache Cârstea, Departamento de Historia Contemporánea, UNED; M. ${ }^{a}$ Luisa de Lázaro Torres, Departamento de Geografía, Uned; David Martín Marcos, Departamento de Historia Moderna, Uned; José Antonio Martínez Torres, Departamento de Historia Moderna, UnED; Íñigo García Martínez de Lagrán, Departamento de Prehistoria y Arqueología (Prehistoria), UnED; Álvaro Molina Martín, Departamento de Historia del Arte, Uned; Francisco Javier Muñoz Ibáñez, Departamento de Prehistoria y Arqueología (Prehistoria), UNED; Rocío Negrete Peña, Departamento de Historia Contemporánea, UnED; Miguel Ángel Novillo López, Departamento de Historia Antigua, UnED.

CORRESPONDENCIA

Revista Espacio, Tiempo y Forma

Facultad de Geografía e Historia, UNED

c/ Senda del Rey, 7

28040 Madrid

e-mail: revista-etf@geo.uned.es 



\section{SUMARIO · SUMMARY}

\section{VOLUMEN I}

13 Artículos $\cdot$ Articles

15 Patricia A. Argüelles Álvarez

Peligros, inseguridades y problemas del viajero visigodo

Danger, Lack of Safety and Problems for the Visigothic Traveller

37 Carmen Barceló, Ana labarta, Josep Benedito \& José M. Melchor Cuatro cerámicas con epigrafía árabe del Museu de Borriana

Four Ceramic Pieces with Arabic Inscriptions in the Archeological Museum of Borriana

65 Carlos Barquero Goñ

Organización de la Orden de San Juan en Castilla durante los siglos XII y XIII The Organization of the Order of Saint John in Castile during the Twelfth and Thirteenth Centuries

113 Francisco de Paula Cañas Gálvez

Una infanta de Navarra en la corte de Castilla: escenarios políticos en torno a la configuración y evolución del Hostal y la casa de Blanca de Trastámara, Princesa de Asturias (I424-†I464)

A Princess of Navarre in the Court of Castile: Political Scenarios in the Configuration and Evolution of the Hostal and Royal Household of Blanca of Trastámara, Princess of Asturias (I424-†I464)

165 David Caramazana Malia

Las promociones artísticas de Alonso de Ejea, arzobispo y administrador perpetuo de la Archidiócesis de Sevilla y patriarca de Constantinopla (I403-I4I7)

The Artistic Patronage of Alonso de Ejea, Archbishop and Perpetual Administrator of the Archdiocese of Seville and Patriarch of Constantinople (I403-I4I7) 
203 Pedro Castillo Maldonado

Privilegios episcopales: la inviolabilidad de los obispos visigóticos y el delito de lesa majestad

Episcopal Privileges: The Inviolability of Visigothic Bishops and the Crime of Lèse-Majesté

227 Máximo Diago HERnANDO

Alonso de Fonseca, Obispo de Ávila, Cuenca y Osma, y el ascenso de un linaje de exiliados portugueses en la Castilla de los siglos XV y XVI Alonso de Fonseca, Bishop of Ávila, Cuenca and Osma, and the Promotion in Castile of an Exiled Noble Family from Portugal during the Fifteenth and Sixteenth Centuries

263 Antonio PIO DI Cosmo

Santa Brigida ed il Monte Gargano: un paesaggio dell'anima. La descrizione dell'ambiente come stratagemma d'ammaestramento morale Saint Brigid and Mount Gargano: A Landscape of the Soul. The Description of the Environment as a Device for Moral Instruction

Santa Brígida y el Monte Gargano: un paisaje del alma. La descripción del medio ambiente como estrategia de entrenamiento moral

293 FERRAN ESQUiLACHE

La 'fila' de agua valenciana y otras medidas de aforo. La verdadera naturaleza de un sistema de medición de caudales de origen andalusí

The Valencian Water 'Fila' and other Systems of Gauging Liquid Capacity. The Actual Nature of a Measurement System of Water Flow of Andalusí Origin

323 Alejandro Esteban Álvarez

Habices del Reino de Granada averiguados en I528 y I53I: la țā‘a nazarí de Órgiva (Alpujarra)

Habices of the Kingdom of Granada Ascertained in 1528 and I53I: The Nasrid tạa'a of Órgiva (Alpujarra)

359 Javier Gómez Gómez e Iñakı Martín Viso

Rationes y decimas: evidencias sobre la gestión de las sernas en el siglo Xl en el noroeste de la Península Ibérica

Rationes and Decimas: Some Evidences on the Management of Eleventh Century Sernas in Northwestern Iberia 
383 Santiago González Sánchez

Aportaciones de Paredes de Nava a las campañas militares del Infante Don Fernando, señor de la villa y regente de Castilla, contra el Reino Nazarí de Granada en I407 y en I4IO

The Contribution of Paredes de Nava to the Military Campaigns of the Infante Fernando, Lord of the Town and Regent of Castile, against the Nasrid Kingdom of Granada in 1407 and I4IO

429 ANTONI LLIBRER ESCRIG

Una máquina para la industria medieval. Los batanes del sur valenciano: integración y negocio. Nuevas aportaciones (I49O-I502)

A Machine for Medieval Industry. The Fulling Mills of the Valencian South: Integration and Business. New contributions (I49O-I502)

455 José Miguel López Villalba

Comunicación escrita y oral de la ordenanza municipal (siglos XV-XVI) Written and Oral Communication of Municipal Regulations (FifteenthSixteenth Centuries)

501 Emilio Martín Gutiérrez

El aprovechamiento de los recursos naturales: la grana en Andalucía occidental durante el siglo XV

The Use of Natural Resources: Grana Pigmentin Western Andalusia during the Fifteenth Century

\section{VOLUMEN II}

537 Vera-Cruz Miranda Menacho

Las finanzas de un heredero: Carlos de Aragón y Navarra (I42I-I46I)

A Crown Prince's Finances: Charles of Aragon and Navarre (I42I-I46I)

569 Raúl Morales Muñoz

Hacia una revalorización del conciliarismo hispano bajomedieval: el Defensorium Trium Conclusionum de Alfonso de Madrigal

Towards a Reappraisal of Late-Medieval Hispanic Conciliarism: Alfonso de Madrigal's Defensorium Trium Conclusionum 
605 David Nogales Rincón

Enrique III de Castilla (I390-I406) y la indagación de rentas: un proyecto regio para la búsqueda de mineros y tesoros a inicios del cuatrocientos Enrique III of Castile (I390-I406) and the Inquiry into Sources of Revenue: A Royal Project for the Quest of Mines And Treasures at the Turn of the Fifteenth Century

647 Gonzalo Oliva Manso

Seisenes y novenes. Tiempos de calma para la moneda castellano-leonesa (I282-I3I2)

The Seisén and the Novén. Times of Stability for the Castile-Leonese Currency (I282-I3I2)

685 Alberto Peña Fernández y Manuel García Alonso Una inscripción medieval inédita en la iglesia de San Miguel de Aguayo (Cantabria)

A Newly Found Medieval Inscription in the Church of San Miguel de Aguayo (Cantabria)

713 Rodrigo Pousa Diéguez

Configuración institucional de una villa costera: Muros en el tránsito de la Edad Media a la Edad Moderna

The Institutional Development of a Coastal Village: Muros between the Middle Ages and the Early Modern Times

745 Juan A. Prieto Sayagués

Las profesiones femeninas de la nobleza y de las oligarquías urbanas en la Castilla bajomedieval. Causas, dinámicas, privilegios y donaciones

Female Professions among the Nobility and the Urban Oligarchy in Late Medieval Castile. Causes, Dynamics, Privileges and Donations

815 María del Pilar Rábade Obradó

El miedo a la Inquisición en la Castilla de los Reyes Católicos

Fear of the Inquisition in Castile under the Catholic Monarchs

845 Carlos Manuel Reglero de la Fuente

EL abad contra el rey (y los regidores): conflicto de jurisdicciones y ejercicio del poder en Sahagún (I398-I4I7)

The Abbot versus The King (and the Town Councillors): Conflict between Jurisdictions and the Use of Power in Sahagún (I398-I4I7) 
881 Manuel Alejandro Rodríguez de la Peña

Eusebius and Alcuin on Constantine and Charlemagne as Wise Rulers:

Sapiential Rulership in Late Antiquity and the Early Middle Ages

Constantino y Carlomagno como gobernantes sabios en la obra de Eusebio de Cesarea y Alcuino de York: la realeza sapiencial en la Antigüedad Tardía y la Alta Edad Media

915 Antonio SÁnchez González

El Archivo de los Mariscales de Castilla y Marqueses de Malagón

The Archives of the Marshals of Castile and the Marquises of Malagón

\section{Estudios y comentarios}

951 Serafín Olcoz Yanguas

Apostilla al estudio Influencia de las redes nobiliarias en la expansión cristiana del siglo XII: el caso de Soria (ETF, 33, 2020)

Notes on the Article The Influence of Aristocratic Networks on the Christian Expansion of the Twelfth Century. The Case of Soria $(E T F, 33,2020)$

\section{Libros $\cdot$ Books}

969 CASTRIllo CASAdo, Janire, Las mujeres vascas durante la Baja Edad Media (María Jesús Fuente)

973 Crónica del rey Juan II de Castilla. Minoría y primeros años de reinado (I406I420). Garcia, Michel (edición y estudio) (Víctor MuÑoz Gómez)

981 Da Silva, Marcelo Cândido, História Medieval (Diego Carlo Améndolla SPÍNOLA)

987 Galende Díaz, Juan Carlos y Ávila SeoAne, Nicolás, El rodado regio hispánico. Fernando III de León y Castilla (I23O-I252) (MAURicio Herrero JIMÉNEZ)

989 GARcía IzQuiERdo, Iván, Frontera, fuero y concejos. El valle del Riaza en la Edad Media (siglos VIII-XII) (CARLOS BARQUERO GOÑI)

993 García IzQuierdo, Iván y Peterson, David (coords.), Camino y Señorío. Obra selecta de Luis Martínez García (Enrique Cantera Montenegro) 
995 González Paz, Carlos Andrés, O Bispado de Mondoñedo na Idade Media. Territorio, comunidade e poder (ENRIQue CANTERA Montenegro)

997 López Martínez, Amalia, Minutarios notariales de Estevo Pérez (Ourense, siglo XIV) (José Miguel López Villalba)

999 Miranda García, Fermín y López de Guereño Sanz, María Teresa (eds.), La muerte de los príncipes en la Edad Media. Balance y perspectivas historiográficas (ANA Echevarría Arsuaga)

1003 Motis Dolader, Miguel Ángel, Vivencias, emociones y perfiles femeninos. Judeoconversas e Inquisición en Aragón en el siglo XV (ANA EcheVARRía ArSUAGA)

1007 Solórzano Telechea, Jesús Ángel y Martín Pérez, Fernando (coords.), Rutas de comunicación marítima y terrestre en los reinos hispánicos durante la Baja Edad Media. Movilidad, conectividad y gobernanza (ENRIQUe José Ruiz Pilares)

1013 Torre, Sandra de la - Etxeberria, Ekaitz - Díaz de Durana, José Ramón (coords.), Valer más en la tierra. Poder, violencia y linaje en el País Vasco bajomedieval (EnRIQue CANTERA Montenegro)

1015 TRIllo SAN José, Carmen, La Vega de Granada a partir de documentación árabe romanceada inédita (I457-I494). Estudio, edición e índices (INMACULADA GONZÁlez SopeÑA)

1019 Val Valdivieso, M. ${ }^{a}$ Isabel - Villanueva Zubizarreta, Olatz (Coords.), Pero Ansúrez. El conde, su época y su memoria (Enrique CANTERA Montenegro)

1021 Villanueva Morte, Concepción y Fernández de Córdova Miralles, Álvaro, El embajador Claver. Diplomacia y conflicto en las «Guerras de Italia» (I495-I504) (ENRIQUe CANTERA MONTENEGRO)

1023 Normas de publicación · Authors Guidelines 


\section{ARTÍCULOS · ARTICLES}

\section{VOLUMEN I}





\title{
UNA MÁQUINA PARA LA \\ INDUSTRIA MEDIEVAL. LOS \\ BATANES DEL SUR VALENCIANO: \\ INTEGRACIÓN Y NEGOCIO. NUEVAS \\ APORTACIONES (1490-1502)
}

\section{A MACHINE FOR MEDIEVAL INDUSTRY. THE FULLING MILLS OF THE VALENCIAN SOUTH: INTEGRATION AND BUSINESS. NEW CONTRIBUTIONS (1490-1502)}

\author{
Antoni Llibrer Escrig ${ }^{1}$ \\ Recepción: 2020/09/06 · Comunicación de observaciones de evaluadores: 2020/09/25 . \\ Aceptación: 2020/09/28 \\ DOI: https://dx.doi.org/10.5944/etfiii.34.2021.28198
}

\section{Resumen ${ }^{2}$}

El artículo tiene como objetivo el estudio de la región batanera de las comarcas del sur valenciano a través de nuevas aportaciones documentales. A lo largo del siglo XV y principios del siglo XVI, en las comarcas de la Vall d'Albaida, el Comtat y Alcoià el número de batanes hidráulicos aumentó hasta los 38 molinos en funcionamiento. El artículo muestra las causas de esta concentración, explica las características técnicas que aportan los documentos, y la adaptación de los batanes al conjunto de la red molinar de la zona. El trabajo concluye explicando los sectores sociales y económicos (artesanos empresarios) que organizaron y protagonizaron este desarrollo técnico e industrial, aportando ejemplos directos de las fuentes mediante análisis prosopográficos.

\section{Palabras clave}

Molino batán; industria textil; artesanos-empresarios; reino de Valencia; siglo XV.

1. Universitat de València. C.e.: j.antonio.llibrer@uv.es

2. Este trabajo ha surgido en el marco del proyecto Entreprises rurales en Méditerranée occidentale, XIII -XVe siècles (ERMO), 2014-2017, organizado por la Casa Velázquez de Madrid, y coordinado por la prof. Catherine Verna (Université Paris 8). 


\begin{abstract}
This aim of this article is to study the fulling-mill area in the southern districts of Valencia, through new discoveries in archival research. Throughout the fifteenth and early sixteenth centuries, in the districts of Vall d'Albaida, Comtat and Alcoià, the number of the water-powered fulling mills increased to 38 operative machines. This article shows the causes of this concentration, explains the technical characteristics provided by the documents, and the adaptation of the fulling mills to the mill network of the region. It concludes by explaining the social and economic sectors (comprised of entrepreneurial artisans) that organized and managed this technical and industrial development with direct examples of the sources by way of a prosopographic analysis.
\end{abstract}

\title{
Keywords
}

Fulling Mill; Textile Industry; Entrepreneurial Artisans; Kingdom of Valencia; Fifteenth Century. 


\section{PLANTEAMIENTO}

Ninguna otra máquina, como el batán, activó, de forma tan trascendente, el sector industrial clave del mundo medieval y moderno. Sin embargo, el desconocimiento que tenemos de estos ingenios no va acorde a su importancia histórica y económica. Si bien han sido muy numerosos -y lo siguen siendo- los trabajos publicados sobre los molinos de cereal, la desproporción respecto al interés que han despertado los «otros» molinos es manifiesta, hasta el punto que el concepto «molino» parece referir, por regla general, al artefacto harinero, y así se deduce de la lectura de una amplia bibliografía 3 . Es cierto que la presencia en el paisaje medieval de los casales con las mazas para el enfurtido de paños no era tan frecuente como la de los que contenían las grandes muelas de piedra, ni tampoco su uso social era tan intenso, ni remitía a una necesidad básica como la elaboración de las harinas panificables. Todo ello contribuye, también, a la mayor dificultad para localizar en las fuentes estas instalaciones, que pierden visibilidad a favor de la molienda de cereal que, desde muy pronto, fue organizada, reglamentada y fiscalizada desde el poder feudal. El abatanado de los paños mediante el uso de estos artefactos quedaba restringido a ciertas áreas muy concretas de desarrollo manufacturero textil ${ }^{4}$.

Pero también es cierto que la presencia de un batán hidráulico manifestaba importantes aspectos económicos: indicaba la opción por unas actividades industriales de importante valor añadido, por una actividad textil pañera con cierto nivel de calidad destinada al mercado, y, sobre todo, el golpeo de las mazas sobre los paños para enfurtirlos tras el tejido representaba la articulación y consolidación de sectores sociales que tenían la capacidad de construir o mantener estas instalaciones, y que no sólo tenían su origen en la clase feudal, sino también en dinámicos grupos de artesanos emprendedores o mercaderes que desarrollaban interesantes estrategias precapitalistas de negocio a partir de estas máquinas 5 .

El objetivo de este artículo es aportar luz sobre la expansión de estos ingenios y sus implicaciones socioeconómicas en ciertas áreas del país valenciano, a través de fuentes documentales que nos permiten conocer de forma directa las características y la gestión de estas instalaciones ${ }^{6}$. Pero el interés de tales

3. Y así lo recuerdan MartíneZ, María: «Construcción y tipos de molinos hidraúlicos (s. XIII-XV)», Mayurqa, 22 (1989), pp. 401-413, y HeRnÁNDEZ, Ricardo: La industria textil en Palencia durante los siglos XVI y XVII. Valladolid, Universidad de Valladolid, 2007, pp. 76-77.

4. Malanima, Paolo: I piedi di legno. Una macchina alle origini dell'industria medioevale. Milán, Franco Angeli, 1988.

5. SICARD, Germain, Aux origines des sociétés anonymes. Les moulins de Toulouse au Moyen Age, Armand Colin, París, 1953; MUNRO, John: «Industrial energy from water-mills in the European economy, 5th to 18th Centuries: the limitations of power», Economia e energia, secc. XIII-XVIII. Atti della Settimana di Studi, Prato, CAVACIOCCHI, Simoneta (ed.), Florecnia, Le Monnier, 2002, pp. 223-269.

6. Adelantamos dato de alguna de estas referencias en LLIBRER, Antoni: Industria textil y crecimiento regional: Ia Vall d'Albaida y el Comtat durante el siglo XV. Universitat de València, 2014, pp. 73-94. 
documentos no reside tanto en su excepcionalidad, -aunque, como decíamos, no es fácil localizar ni rastrear los contratos asociados a estos molinos-, sino en su contextualización, en la medida que hemos podido enmarcar su uso y su función económica en el conjunto del área batanera de las comarcas del sur valenciano, y además, hemos podido conocer a sus protagonistas -arrendatarios, arrendadores, o compradores y vendedores- gracias a los análisis prosopográficos que, desde hace más de una década, estamos llevando a cabo en las villas de las comarcas del sur valenciano.

A su vez, tampoco las máquinas son entes aislados; los batanes citados en los documentos que ofrecemos en el apéndice no son artefactos solitarios que nos han aparecido de forma casual en la documentación, sino que forman parte de un auténtico distrito batanero asociado al desarrollo textil pañero que se articuló en las comarcas meridionales de l'Alcoià, el Comtat y la Vall d'Albaida a lo largo de todo el siglo XV y la primera mitad del XVI, alrededor de villas como Cocentaina, Alcoi, Ontinyent, Bocairent, Albaida, Planes o Penàguila, y que lógicamente nos permiten explicar el origen, la función y la trascendencia económica de tales instalaciones.

En realidad, a pesar de la importancia y significado de estas máquinas, no ha habido en el medievalismo peninsular una auténtica tradición historiográfica que se ocupara, de forma central, de los batanes. Es cierto que contamos con algunos trabajos de carácter microhistórico, de estudios locales de algún casal de batán en villas o áreas periurbanas, que son importantes en la medida que comienzan a descubrir el paisaje bajomedieval que formaban estos otros molinos, y que aportan información sobre formas de uso, explotación, posible registro arqueológico, etc ${ }^{7}$. Sin embargo, faltan estudios más amplios desde el punto de vista regional, que cubran áreas extensas de infraestructura molinar, que tiendan a la fijación de un mínimo inventario de batanes en ciertas cuencas fluviales, de la misma forma que se ha realizado sobre los molinos harineros, o, al menos, en coordinación con el interés despertado, desde hace décadas, por las reconstrucciones de las cadenas de molinos de cereal.

7. Puede encontrarse esta variada bibliografía local en MARTínez, María: «Desarrollo historiográfico de la molinería hidráulica en la España medieval: perspectivas y resultados», en GALETTI, Paola \& RACINE, Pierre (coords.) / mulini nell'Europa medievale. Bolonia, Clueb, 2003, pp. 104-139; y en CóRDOBA, Ricardo: «Los batanes hidráulicos de la cuenca del Guadalquivir a fines de la Edad Media. Explotación y equipamiento técnico», Anuario de Estudios Medievales, 41/2 (2011), pp. 593-622. 
Los trabajos de Ricardo Córdoba de la Llave ${ }^{8}$, María Martínez ${ }^{9}$, Margalida Bernat $^{\text {I0 }}$, Antonio Mira ${ }^{\mathrm{II}} \mathrm{y}$ Joaquín Aparici ${ }^{\mathrm{I2}}$ suponen, sin duda, un sólido inicio del interés metodológico por estas instalaciones, y tanto desde el punto de vista técnico (con la necesaria reconstrucción de los elementos que configuran la máquina), como del económico y social. Sus trabajos de reconstrucción ofrecen ya este interés por un acercamiento «regional» a los batanes que supere los datos solitarios ofrecidos, en ocasiones por la arbitrariedad documental; un acercamiento regional que permita contextualizar los ingenios y descubrir su función económica en relación al crecimiento de las actividades manufactureras en determinados periodos y regiones. Desde este planteamiento metodológico pretendemos aportar nuevas informaciones sobre la red de batanes hidráulicos del sur valenciano.

\section{LA REGIÓN BATANERA DE LAS COMARCAS DEL SUR Y SU RAIIZ INDUSTRIAL}

Desde el último cuarto del siglo XIV, la conjunción de diversos factores permitió el desarrollo de una importante área pañera industrial en el conjunto de las actuales comarcas de la Vall d'Albaida, el Comtat i l'Alcoià, y, que, entre otros elementos clave, supuso el funcionamiento de hasta 38 batanes hidráulicos a principios del siglo XVI. Estas tres comarcas configuran en realidad un espacio geográfico homogéneo rodeado por diversas sierras, y cruzado por dos ríos que salvan importantes desniveles, y cuyo aprovechamiento hidráulico fue muy

8. Junto al trabajo anterior, CóRDOBA, Ricardo: «Aceñas, tahonas y almazaras. Técnicas industriales y procesos productivos del sector agroalimentario en la Córdoba del siglo XV», Hispania, 48/170 (1988), pp. 827-874; Idem: «Aportaciones de la documentación gráfica y escrita al estudio arqueológico de las instalaciones industriales de época medieval y moderna», en García, Alberto (ed.): Arqueología de la producción en época medieval. Granada, Alhulia, 2013, pp. 43-70.

9. Martínez, María: «Construcción y tipos de molinos...; Idem: «Desarrollo historiográfico...; Idem: «Construcción y tipos de molinos hidráulicos en Murcia (ss. XIII-XV)», Actas del V Congreso de la Sociedad Española de Historia de las Ciencias y de las Técnicas, Murcia, 1989, Valera \& López, Carlos (coords.), Murcia, vol. I, 1991, pp. 385-400.

10. Bernat, Margalida: «Molins drapers a ciutat de Mallorca: entre interessos polítics i econòmics», Estudis Baleàrics, 58-59 (1987), pp. 127-150; Idem: Els «III Mesters de la Llana». Paraires, teixidors de llana i tintorers a Ciutat de Mallorca (s. XIV-XVII), Palma de Mallorca, IEB, 1995; Idem: «Los batanes de Ciutat de Mallorca (siglos XIII-XVII)», en VII Congreso Internacional de Molinología, Zamora, Universidad de Salamanca, 2010, pp. 406-415.

11. Debemos destacar su trabajo, MıRA, Antonio: «La organización de la red molinar en la Vall d'Albaida y l'Alcoià a finales de la Edad Media. Infraestructura industrial, desarrollo económico y fiscalidad», en GLICK, Thomas, GUINOT, Enric \& MARTínez, Pablo (eds.): Els molins hidràulics valencians. Tecnologia, història i context social. Valencia, Diputació, 2000, pp. 229-271; y también Idem: Entre la renta y el impuesto. Fiscalidad, finanzas y crecimiento económico en las villas reales del sur valenciano (siglos XIV-XVI). València, PUV, 2005. Glick ya descubrió la importancia e integración de los batanes en la red molinar valenciana, GLICK, Thomas: Regadío y sociedad en la Valencia medieval. Valencia, Del Cenia al Segura, 1988.

12. ApARICI MARTí, Joaquín, El Alto Palancia como polo de desarrollo económico. El sector de la manufactura textil, Ajuntament de Sogorb, 2001; Idem: «Paños, tintes y batanes: mapa de la producción textil medieval en la zona septentrional del Reino de Valencia», Boletín de la Sociedad Castellonense de Cultura, 86 (2010), pp. 185-212; Idem: «Capilaridad de la manufactura textil en la Plana de Castelló. El caso de Onda en el siglo XV», Anuario de Estudios Medievales, 40-1 (2010), pp. 181-199. 
temprano (disponemos de noticias ya a inicios del siglo XIII). No obstante, será en el último cuarto de la centuria siguiente cuando se implementen diversos factores que propicien la configuración, observable a lo largo de todo el siglo $\mathrm{XV}$ y principios del XVI, de un auténtico distrito manufacturero. El crecimiento de una actividad ganadera ovina, a la que se dedicaban centenares y centenares de familias de las alquerías y aljamas de estas sierras del interior, que facilitaron un activo comercio de lanas; la presencia secular en las comunidades y en las familias campesinas de una manufactura rural de base (que facilitaba el trabajo de la lana) para el consumo doméstico, pero que permitía la adquisición de un saber técnico y de un instrumental básico para el trabajo de las fibras, y para el aprovechamiento de la mano de obra intrafamiliar; el crecimiento demográfico a lo largo de todo el siglo XV, ya ampliamente demostrado, en todo el conjunto del sur del reino, no hizo sino articular importantes mercados interiores que demandaban bienes de consumo de calidades medias-altas, y cuyo destino eran comunidades campesinas pero también ciudades y villas como Alacant, Vila Joiosa, Elx, Xàtiva, Gandia, Oliva, Dénia o Pego; se fue configurando así una demanda de textiles con ciertos parámetros de calidad estándar, y que exigían el cardado, el tundido, el tintado y el abatanado de los paños; una mejora de los rendimientos agrícolas en estas comarcas del sur, también estudiada y analizada ya, permitió a las familias campesinas liberar activos, y trasvasar mano de obra hacia el sector de una industria textil en crecimiento, formando ya empresas artesanales especializadas, que sobrepasaban el estrato inicial de la manufactura para el autoconsumo, y que producían para el mercado; la configuración de un grupo artesanal emprendedor (formado esencialmente por pelaires y pañeros más activos, con empresas más diversificadas, y que controlaban los procesos de acabado del paño) permitió aportar el capital necesario para las inversiones de mayor riesgo, como las que suponían el acceso a las tintorerías, a las almazaras, a los tiradores o a los batanes; pero a su vez, este grupo emprendedor generó un considerable crecimiento de la actividad poniendo en marcha el ciclo de producción del paño distribuyendo lana a pequeños productores y activando sistemas de trabajo por encargo -cercanos al putting-out-system o verlagssystem- que multiplicaron el número de talleres y trabajadores del sector ${ }^{\mathrm{I3}}$; finalmente, como otro de los factores cuya combinación generó este distrito industrial textil, la particular hidrografía de la zona, formada por cursos cortos pero muy nerviosos, alimentados además de una pluviometría superior a la media, permitió su aprovechamiento molinar, con más de un centenar de aparatos (de todo tipo de molinos) en las primeras décadas del siglo XVI, y

13. En diversos trabajos hemos explicado con detalle este conjunto de factores que permitieron la configuración de este distrito pañero, LLIBRER, Antoni: Los orígenes de la industria de la lana en la baja Edad Media. El Comtat en el siglo XV. Valencia, Generalitat, 2007; Idem: «La configuració d'un districte industrial a la baixa Edad Mitjana. Les viles draperes de la Vall d'Albaida, l'Alcoià i el Comtat», Recerques: Història, Economia, Cultura, 64 (2013), pp. 5-31; Idem: Industria textil..., pp. 47-101. 
configuró, sin duda, una de las mayores concentraciones de estos artefactos en toda la Corona de Aragón.

Desde, al menos, la segunda mitad del siglo XIII, conocemos un interesante aprovechamiento molinar de esta área del sur. En esa cronología se conocen en uso cuatro molinos harineros en término de Ontinyent, uno en Bocairent, tres en Alcoi y cinco en el ámbito de la villa de Cocentaina ${ }^{\mathrm{I}}$. La evolución en la construcción de nuevos molinos harineros no dejará de aumentar a lo largo del siglo XIV, pero será durante la centuria siguiente cuando se llevará a cabo la instalación del gran número de batanes que formarán esta área molinar industrial, sin duda a la par que se consolidaba la manufactura pañera de la zona.

La red hidrográfica de la región venía configurada por tres áreas que generaron diferentes espacios de ubicación de batanes. Una al norte (vid. Figura I), drenada por el riu d'Albaida, que, desde su nacimiento en la sierra de Benicadell, atraviesa toda esta área septentrional junto a las villas de Ontinyent, Agullent y Albaida mientras continúa hacia el norte; en estos dos últimos núcleos será su afluente más importante, el Clariano, el que se convertirá en un auténtico espacio de explotación molinar, esencialmente batanero, pero también de otros tipos de ingenios ${ }^{15}$. A mediados del siglo $\mathrm{XV}$, funcionaban ya en esta primera zona ocho batanes, pero en el periodo de máximo aprovechamiento, a principios del siglo XVI, hasta veinte batanes estarán en activo ${ }^{16}$. La segunda área corresponde al espacio central de la región, atravesado y drenado por el Serpis, también llamado riu d'Alcoi o Molinar, según tramos; nacido cerca de la villa de Alcoi, entre las sierras de la Font Roja y la Carrasqueta, desde su inicio debe salvar importantes desniveles de cota, y a su paso por Cocentaina, sólo io $\mathrm{km}$ después, aumenta su potencia con las aportaciones de los ríos Frainos y Agres, antes de circular, cerca de Planes, y a través del valle de Orxa, hacia la costa, a la comarca de la Safor, donde desemboca cerca de Gandía; a lo largo de la primera mitad del siglo XV, en este segundo sector molinar se habían instalado cinco molinos pañeros, pero hasta quince batanes funcionarán aquí de forma simultánea en las primeras décadas del Quinientos, y son conocidas las desviaciones que se realizaban en determinados puntos de su cauce para optimizar su uso industrial ${ }^{17}$. La tercera zona remite al sector suroeste

14. Sobre esta primera instalación de molinos harineros conocida en la zona, SELMA, Sergi: «Notes sobre la formació d'uns primers monopolis feudals a la Vall d'Albaida», Alba, 7 (1992), pp. 35-38; TorRó, Josep: (1992) La formación d'un espai feudal. Alcoi, 1245-1304. Valencia, IVEI, 1992, pp. 72-96; MIRA, Antonio: «La organización..., p. 230; FerRAGUD, Carmel: El naixement d'una vila rural valenciana. Cocentaina, 1245-1304. Valencia, PUV, 2003, pp. 57-59 y 154-158.

15. Sobre el aprovechamiento molinar de esta zona al norte, TORRó, Josep: «El molí d'aigua de Descals», Almaig. Estudis i Documents, 6 (1990), pp. 8-15; PínTer, Silvia. (1993) «El molí fariner d’Agullent», Almaig. Estudis i Documents, IX, pp. 56-62; MIRA, Antonio: «La organización..., p. 240-245.

16. MIRA, Antonio: «La organización..., p. 240-245; Idem: Entre la renta y el impuesto..., pp. 53-72.

17. VIDAL, Vicente: Arquitectura e Industria. Un ensayo tipológico de los edificios fabriles del Alcoià. Valencia, Generalitat, 1988; SebAStIÀ, Rafael: «El cauce del río Molinar: vestigio de las primeras fases de la industrialización (Alcoy, Alicante)», Investigaciones geográficas, 24 (2000), pp. 146-160; FERRER, Pere et alii: Molins i moliners: molins hidràulics fariners al Comtat, Cocentaina, CEC, 2007. LLIBRER, Antoni: «La gestió dels batans i el desenvolupament de la indústria tèxtil al segle XV. El cas de l'àrea Alcoi-Cocentaina», Estudis d'Història Agrària, 23 (2012), pp. 231-248. 
de la región pañera, cercana al término meridional de la villa de Bocairent, de Banyeres y, de forma más alejada, a las villas de Biar y Villena, espacio drenado por el primer tramo del Vinalopó; un batán se ubicó aquí durante el primer tercio del siglo XV, pero a principios del Quinientos funcionaron tres molinos de paños.

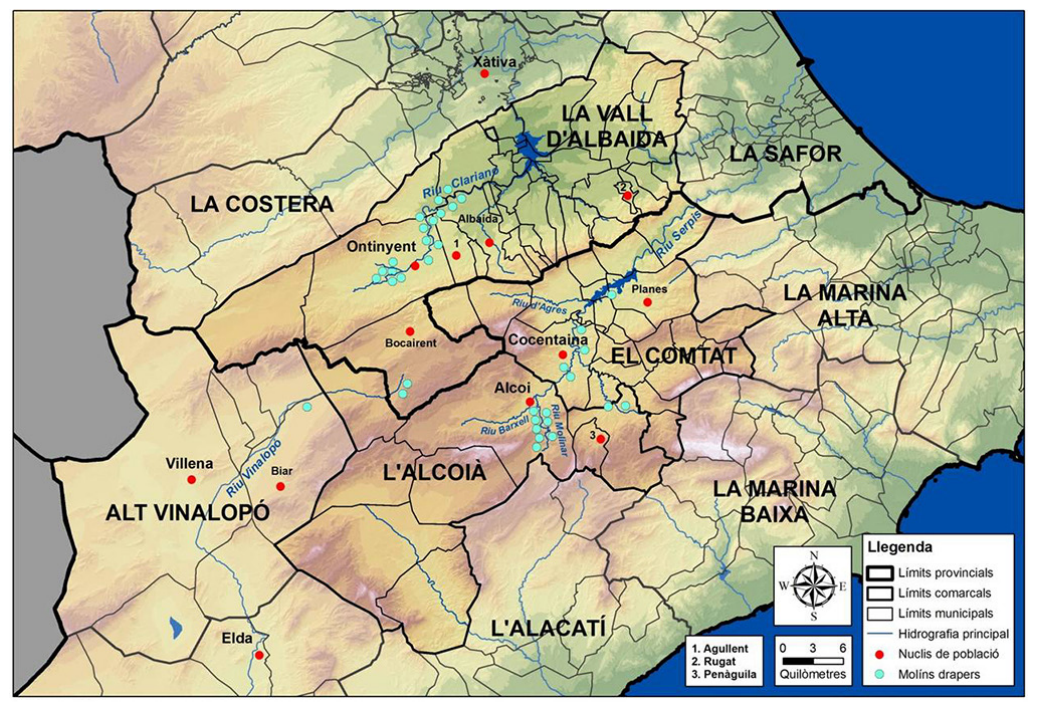

FIGURA 1. DISTRIBUCIÓN DE LOS MOLINOS PAÑEROS EN LAS COMARCAS DEL SUR (1500-1520). Fuente: LLIBRER, Antoni: Industria textil y crecimiento regional: la Vall d'Albaida y el Comtat durante el siglo XV. Universitat de València, 2014, p. 78

Los datos de crecimiento en la infraestructura molinar son claros, y afectan no sólo a los artefactos de golpeo de textiles, también a los harineros, e incluso a los molinos de aceite, o a los llamados «molins esmoladors» (para afilar instrumentos o herramientas cortantes): en ese periodo de máxima expansión molinar de la región, que serán las primeras décadas del siglo XVI, se documentan, al menos, 23 harineros en la zona norte; I7 en el sector de Alcoi-Cocentaina; y I4 en el área suroeste de $\operatorname{Biar}^{18}$. Una suma de todos los ingenios documentados en el conjunto de la región (contabilizando algunos cuya función no ha podido ser identificada) nos da una cifra de IIo molinos ( 54 harineros, 38 batanes, II molinos de aceite, 3 molinos de afilado y 4 molinos más con función no especificada ${ }^{19}$. No parece haberse articulado en

18. Sobre la documentación y localización de tales molinos, MIRA, Antonio: «La organización..., p. 240-245; FerRER, Pere et alii: Molins i moliners..., pp. 119-352; LLIBRER, Antoni: Industria textil..., pp. 79-85.

19. Referencias y cálculos en Llibrer, Antoni: «La gestió dels batans..., pp. 233-240; e Idem: Industria textil..., pp. 79-85. Algunos sencillos detalles comparativos pueden confirmar la importancia de la concentración batanera de esta zona: en el área de la huerta de Valencia funcionaban, en 1527, ocho batanes (Vid. GLICK, Thomas \& MARTíneZ, Luis: «La molineria hidràulica valenciana: qüestions obertes», en GLICK, Thomas, GUINOT, Enric \& MARTínEZ, Pablo (eds.): Els molins hidràulics..., p. 85); en la cuenca del Guadalquivir, entre 1460-1500 funcionaban 20 batanes, número similar al de Segovia en la misma cronología (Vid. CórdobA, Ricardo: «Los batanes hidráulicos..., p. 602); en las dos primeras décadas del siglo XVI, la industria textil palentina enfurtía sus paños en ocho batanes que sumaban un 
toda la Corona de Aragón una iniciativa tecnológica parecida en un espacio tan ajustado. A su vez, hay un dato altamente significativo en cuanto al sentido molinar de esta zona y a su función económica, por el detalle clave que en algunas villas es superior el número de batanes que el de molinos de cereal: en término de Ontinyent funcionaban I7 harineros y I8 batanes; en Alcoi, un harinero y 8 pañeros.

Aunque no siempre se ha podido establecer la localización exacta de algunos de estos batanes (en ocasiones conocemos sólo las partidas rurales donde se ubicaban), la observación y el análisis del conjunto de artefactos de un mismo sector o una misma partida, parecen indicarnos que era frecuente la sucesión casi ininterrumpida de estas máquinas (en ocasiones junto a los molinos harineros), configurando un sistema de aprovechamiento hídrico complementario y consecutivo, que permitía la máxima eficiencia mediante el paso y la circulación del agua de uno a otro aparato gracias a los constantes y, en ocasiones, pronunciados desniveles, en muchos casos de origen antrópico ${ }^{20}$. El funcionamiento de este sistema hasta el siglo XVIII e incluso el XIX no sólo nos permite acercarnos a su diseño y organización bajomedieval (vid. Figura 2), además nos confirma el rendimiento, y la utilidad de tal sistema secular ${ }^{2 \mathrm{I}}$. Pero la clave de esta estructura de aprovechamiento es la necesidad de un complejo nivel de organización, y también de un elevado nivel de capitalización, y no sólo para la construcción de los artefactos, también para su gestión y mantenimiento. A su vez, y esto lo demuestra la documentación, no sólo el poder feudal ejercía una parte de estas funciones, también un conjunto de artesanos y pañeros emprendedores eran los que, como veremos, llevaban el peso de la organización, la gestión y el mantenimiento de esta concentración industrial asociada al desarrollo de la producción textil.

\section{LOS BATANES DEL SUR: INTEGRACIÓN SISTÉMICA}

Desde el punto de vista técnico, la limitada información que nos aportan las fuentes nos indican que la mayoría de los batanes tendían a ubicarse sobre los propios cauces, para tomar así, de forma directa, la energía necesaria a su funcionamiento. En ocasiones se construían presas o azudes, situadas estratégicamente, para generar acumulaciones o desniveles que mejoraran la fuerza de la corriente, y cuya asociación podía generar el aprovechamiento encadenado en varios molinos

total de doce pilas (HERNÁNDEZ, Ricardo: La industria textil.., pp. 76-77); el cronista ilustrado Tomás Ricord afirma en su «Noticia de la varias y diferentes producciones del reino de Valencia, como también de sus fábricas y artefactos, según en el estado que tenían en el año 1791», que en el reino había ese año 71 batanes en los que trabajaban 109 operarios; tales artefactos se distribuían en pocos centros textiles: Valencia, Bunyol, Segorbe, Onil, Alcoi, Ontinyent, Bocairent, Castalla, Alzira y Morella (ed. facsímil Librería París-Valencia, 1990, p. 79).

20. Este sistema de molinos «en cadena» no era infrecuente en el paisaje medieval, lo encontramos también en el área batanera del Guadalquivir, vid. CÓRDOBA, Ricardo: «Los batanes hidráulicos..., p. 590-600; en la zona italiana de Calci se dio un ejemplo modélico, vid. PANDURI, Tiziana: "Como Acqua de mola». Mulini ad Acqua nel territorio de Calci in età medievale. Pisa, Università, 2001.

21. VIDAL, Vicente: op. cit., pp. 70-86. 
consecutivos $^{22}$. Todo parece indicar que estamos ante un sistema planificado e integrado de aprovechamiento de la mejor de las opciones para el rendimiento de la tecnología del batán; no parece que los ingenios se fueran construyendo de forma anárquica o separada, o se fueran acumulando de forma aislada, sino que se integraban en un sistema hídrico denso desde hacía siglos, y compartiendo recursos y espacio con infinidad de molinos de cereal $^{23}$. No obstante, parece evidente, según las cronologías en que se han documentado, que los batanes llegaron después, y se incorporaron posteriormente a los distintos sistemas de aprovechamiento hídrico ${ }^{24}$. Hasta finales del siglo XIV no tenemos noticia del primer batán en esta zona: en I378 la documentación de Real Cancellería nos da referencia de un molino pañero en el río de Alcoi, en el término de esa villa; a partir de I4I2, ya se documentan cinco batanes en Ontinyent, y uno en Biar; pocos años después, en I4I6, aparece uno más en Bocairent; la primera referencia a un molino pañero en Cocentaina es de I424. A partir de estas fechas iniciales del siglo XV, la construcción de batanes no dejará de aumentar hasta las elevadas cifras, ya citadas, de las primeras décadas del Quinientos ${ }^{25}$. Una acumulación desordenada de batanes, construidos sin una

22. Numerosas noticias parecen confirmar este punto tan complejo. Los detalles de ubicación que nos muestran los documentos refieren siempre al propio río o torrente: quoddam casale molendinum draper meum... confrontatur cum rivo (Documento I del Apéndice); quoddam molendinum mei pilater, situm et positum in termino ville Cocentayne, ad latus rivi de Alcoy (Documento 4). Pero en un caso se cita también acequia propia: quoddam casale molendinos farineri et pilater, sitos in rivo dicte ville,... cum suis roda, pila et cum aqua et cequia (Documento 3). Antonio Mira localiza referencias similares en molinos de Ontinyent, Bocairent o Biar: molí del riu; molí del pont del riu; molí del pou de l'Olla; molí del riuet de Fraynos; molí del Vinalopó; también documenta los azudes y desniveles que eran aprovechados para su ubicación: en la partida del Llombo, de Ontinyent, se construyó l'assut dels molins drapers; otro artefacto se situaba en lo barranc de l'Albellar; también cita el molí d'amunt, o el molí d'enmig, o el molí de baix; asimismo aparece la partida Dels molins del barranc; o dos molinos claramente consecutivos: el molí damunt la bassa major, y el molí davall la bassa major; las referencias en MIRA, Antonio: «La organización..., p. 240-250. También en la misma huerta de Valencia se documentan saltos de agua y azudes de parada asociados a los batanes, GLICK, Thomas: Regadío y sociedad..., pp. 108-129. En el área del Guadalquivir, los batanes se localizaban por las «paradas» (la Parada de Pajares; Parada de San Julián; Parada de Casillas; Parada de Cucarrón, etc.), especie de pasillos artificiales que permitían mayor velocidad del agua para hacer más efectivo el movimiento de las ruedas, CóRdoBA, Ricardo: «Los batanes hidráulicos..., pp. 602-610.

23. La documentación muestra, con la concreción de las partidas de ubicación, cómo los batanes comparten espacio con otros molinos: en las partidas contestanas de Els molins de senyor, de Miralbo, o del Pas de Xàtiva en término de Planes, convivían, en efecto, batanes y harineros; lo mismo ocurría en el riu d'Alcoi; también en el Castellar o la Penya Blanca, en término de Ontinyent; en la séquia de Beneixama en Biar. También se ha observado tal convivencia tecnológica en la huerta de Valencia: a mediados del siglo XV, los molinos pañeros d'en Ferrada y el de Francesc Compte compartían espacio, en la acequia de Mislata, con, al menos, seis harineros; en 1426, en la acequia de Rascanya, se recomienda la construcción de molí o molins així fariners com drapers, com encara arrocers (referencias en GLICK, Thomas: Regadío y sociedad..., pp. 118-129). Algún autor habla de la dificultad de asociar o combinar los batanes, el riego y los molinos de cereal, dado que los primeros consumían mayor cantidad de agua, y además la contaminaban por las sustancias que se utilizaban en las pilas, de esta forma los batanes tendían a ubicarse de forma separada al resto de artefactos molinares, vid. BERnAT, Margalida: «Molins drapers..., pp. 127-150; sin embargo, en esta zona batanera del país valenciano, como también documenta Córdoba para la del Guadalquivir, la convivencia entre distintos tipos de molinos y los regantes parece la tónica general.

24. En el siglo XV, se tenía conciencia clara de la posterior llegada de los batanes al sistema molinar. En un pleito generado en la huerta de Valencia, precisamente por el uso compartido de los recursos hídricos entre propietarios de un batán y diversos harineros, se afirma que estos últimos són molins molt antics de temps de moros e se mostren en cascú de aquella edificis morischs, los que.s per qualsevol vehent aquells, seran haguts per edificis morsichs; mientras el molino pañero es descrito como nou, construït ab tres canals nauts o piles per obrar (detalles del pleito en GLICK, Thomas: Regadío y sociedad..., pp. 121-129).

25. MirA, Antonio: «La organización..., pp. 235-240; Llibrer, Antoni: «La gestió dels batans..., pp. 233-245. Evolución cronológica similar se observa en otras áreas del reino, aunque con menor presencia final: en Alzira se documenta un 
mínima planificación sistémica, hubiera hecho muy difícil, no sólo la construcción de azudes o saltos de agua, también la misma convivencia de las distintas instalaciones que pretendían aprovechar la misma fuente energética ${ }^{26}$. Y aquí surge, por un lado, la presencia del poder feudal, que atiende a la construcción de los casales, pero sobre todo, surge la importante acción gestora de los pañeros y artesanos, del capital industrial que protagonizó socialmente esta magna iniciativa técnico-industrial, y que, desde los propios casales y molinos que gestionaban (que eran la mayoría, y tanto batanes como harineros), podían establecer una organización adecuada de todo el amplio sistema.

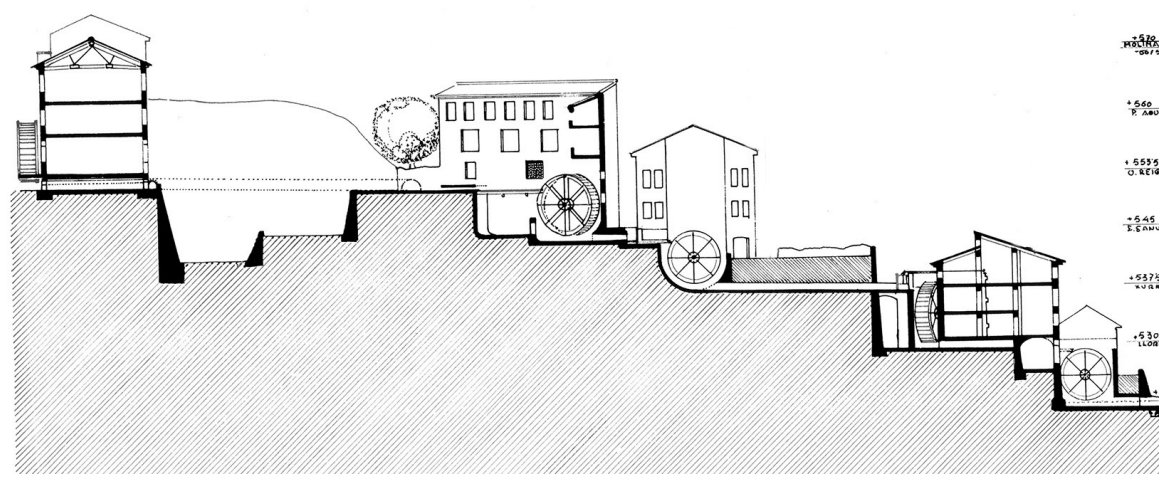

FIGURA 2. RECONSTRUCCIÓN DE LOS BATANES Y ESPACIOS FABRILES DE UN SECTOR DE EL MOLINAR, ALCOI (S. XVIII-XIX). SISTEMA DE APROVEChAMIENTO CONSECUtIVO. Fuente: VIDAL, Vicente: Arquitectura $e$ Industria. Un ensayo tipológico de los edificios fabriles del Alcoià. Valencia, Generalitat, 1988, p. 86

molino harinero y batán en 1377; otro casal que comparte las dos funciones es localizado en 1399 junto a otro idéntico en 1407 (MARTínez AraQUE, Iván: En els orígens de la indústria rural. L'artesanat a Alzira i la Ribera en els segles XIII-XV. Valencia, PUV, 2012, pp. 82-84); en Castelló se documentan censos por un molí draper desde 1480 (VICIANO, Pau: Els cofres del rei. Rendes i gestors de la batllia de Castelló (1366-1500). Valencia, Afers, 2000, pp. 57-58 y 164), y en 1493 se reforma un molino harinero para convertirlo en pañero, aunque en Almassora, a $4 \mathrm{~km}$ de Castelló, hay noticia de un batán ya en 1396 (en un mismo caserón se albergaban dos molinos harineros y el batán que estuvo en activo, al menos, hasta 1480, y donde se enfurtían los paños elaborados en la villa de Castelló); en Onda, hay noticias de un batán en 1470; en Segorbe, los dos batanes (situados prope rivuum dicte civitatis Sugurbi) se documentan en funcionamiento entre 1440 y, al menos uno ellos hasta,1515; en Jérica funcionó un batán entre 1378 y 1490 (en 1407 su propietario, un pelaire local, pide a la villa la construcción de un azud para mejorar la captación de agua para su molino); todas las referencias de las comarcas de Castelló en APARICI, Joaquín: «Paños, tintes y batanes..., pp. 185-212; Idem: «Capilaridad de la manufactura..., pp. 181-199. En Llíria, a 25 km al interior de Valencia, funcionaba un batán en 1388, situado cerca del azud de la acequia Mayor, y que está documentado a lo largo de todo el siglo XV (LLIBRER, Antoni: El finestral gòtic. L'església i el poble de Llíria als segles medievals. Valencia, Ajuntament de Llíria, 2003, pp. 144-146).

26. Pensemos que la construcción de un batán sin una mínima planificación o valoración previa de todo el conjunto de una misma zona hídrica podría generar importantes problemas y conflictos para todos los miembros del sistema, tanto molinos como regantes. Así lo testifica Glick en los numerosos pleitos documentados precisamente porque los propietarios decidían cambiar, de manera arbitraria, la forma de molienda o la tecnología y función de sus molinos, lo que contribuía a alterar el equilibrio hídrico general (produciendo retrocesos, disminuciones, remansos o desbordes de agua que podían hasta destruir canalizaciones). Entre los numerosos conflictos localizados, el autor ofrece el generado en 1446 por el batán d'en Ferrada, en el brazo de Algirós de la acequia de Mestalla, que producía constantes acumulaciones y remansos de agua porque su propietario decidió que funcionara con sólo una de las dos ruedas con las que debía ser accionado el batán, vid. GLıck, Thomas: Regadío y sociedad..., pp. 106-131. 
La convivencia de distintos tipos de molinos se confirma porque en ocasiones los casales podían llegar a compartir los dos tipos de máquinas; y no resulta infrecuente la transformación de un molino para cambiar su función. En el documento 3 del apéndice exponemos el arrendamiento llevado a cabo entre dos pelaires contestanos, de cierto casal con un molino de harina y un batán (quoddam casale molendinos fariner et pilater), situado en el río de Alcoi. Los tres batanes de Alzira, ya citados, compartían espacio con las muelas de cereal ${ }^{27}$. Por otro lado, el molino del Pas de Xàtiva, en Ontinyent, documentado como harinero desde I4I2, amplío su funcionalidad incluyendo un batán a partir de I476; el batán de Santa Bàrbara, en la misma villa, documentado desde I4I3, se transformó en molino afilador en I5II; en Bocairent, el molí del Riu fue harinero hasta I5I6 en que se transformó en batán ${ }^{28}$.

Tal vez la elección del modelo de batán utilizado, con predominio de una o dos mazas, que exigían instalaciones más modestas, está en relación a esta planificación o a esta adecuación a un sistema de regadío ya muy densificado. Cuando la documentación aporta la información adecuada, observamos que las instalaciones para el abatanado se montaban, de forma general, con una o dos mazas. Dos de los molinos pañeros de Ontinyent son descritos con dos pilas o mazas, igual que dos de los situados en el cauce del Molinar, en término de Alcoi; sin embargo, tres de los ubicados en Cocentaina tenían únicamente una maza ${ }^{29}$.

Instalaciones de batanes con mayor número de mazas (tres, cuatro o más ${ }^{30}$ ) hubieran supuesto posiblemente problemas de adaptación al sistema y, sobre todo, problemas constantes de convivencia con el resto de usuarios (regantes

27. Martínez Araque, Iván: op. cit. pp. 82-84.

28. Iradiel recuerda cómo la rentabilidad de los batanes en un contexto de crecimiento industrial, activaba la transformación de molinos de harineros en pañeros, IRADIEL, Paulino, Evolución de la industria textil castellana en los siglos XIII-XVI. Factores de desarrollo, organización y costes de la producción manufacturera en Cuenca. Salamanca, Univ. Salamanca, 1974, pp. 45-50.

29. Las descripciones documentales, aunque muy concisas, dejan claros tales detalles técnicos: del molí damunt d'Ontinyent de dice que en lo qual ha dos maces (1412); el batán de la Penya Blanca, en la misma villa en 1508, y otros dos en Alcoi en 1523 y 1530, son descritos como molí draper ab dos piles (MıRA, Antonio: «La organización..., pp. 246248). En Cocentina, en cambio, los casos conocidos son descritos con maza única: del batán del Documento 2 en el apéndice, cuya mitad es arrendada entre pelaires, se dice que in toto est una pila; sobre otras referencias a molinos pañeros contestanos, LLIBRER, Antoni: «La gestió dels batans..., pp. 233-245. No disponemos de esta información técnica en relación a otros batanes documentados en otras áreas valencianas, dado que en su mayor parte nos llegan a través de lacónicas referencias documentales indirectas. Conocemos que la mayoría de molinos pañeros en el término de Palencia contaban también con maza única; así como todos los batanes, alrededor de cincuenta en el siglo XIV y de cuarenta en el XV, que enfurtían los paños de la industria florentina, HosHINo, Hidetoshi: «Note sulle gualchiere degli Albizzi nel basso medioevo», en Idem: Industria tessile e commercio internazionale nella Firenza del tardo Medioevo. Florencia, 2001, pp. 61-62.

30. En ámbito valenciano no son ajenos los molinos con hasta seis pilas o mazas, aunque eran preferentemente para el triturado del arroz: en 1357 el molí Blanch, molendinum de arroç, situado en la acequia valenciana de Rascanya, contaba con seis mazas ( $a b$ se sis maces, e ab son arbre e ab sa roda, e ab se sis piles, tot en timó); idéntico número tenía otro molino arrocero cercano, vid. GLICK, Thomas \& MARTínEZ, Luis: «La molineria hidràulica..., pp. 82-83. No olvidemos que el molino arrocero podía transformarse en pañero, y a la inversa, sin excesivos cambios técnicos; así lo autorizó Alfonso XI en 1335 a los vecinos de Murcia ante la escasa demanda de abatanado de paños, IRADIEL, Paulino, Evolución de la industria textil..., p. 47. 
y otros molinos), por las mayores necesidades energéticas ${ }^{31}$. Pensemos que en pocos kilómetros se concentraban decenas y decenas de molinos, y si la ubicación y organización no hubiera sido la adecuada, su supervivencia hubiera sido muy limitada. El diseño de los batanes con rueda vertical podría facilitar a su vez ese uso complementario y sistémico de los recursos. Aunque los documentos apenas aportan prácticamente dato directo alguno que nos permita confirmar tal diseño, todo apunta a que nos encontramos ante batanes con impulsión mediante rueda vertical. En las comarcas del sur valenciano, beneficiadas por la agreste orografía que recorrían sus torrentes y ríos nerviosos, con constantes meandros, y con importantes desniveles que, además, podían intensificarse artificialmente, las ruedas verticales eran, sin duda, la mejor opción técnica. La mejor opción para optimizar el espacio natural, pero complementada con la acción antrópica (mediante el trazado de azudes, la construcción de muros, el incremento de los niveles de cota de los saltos, etc.), y además beneficiada por una pluviometría superior a la media valenciana.

En otros ámbitos peninsulares los batanes se accionaban de idéntica forma, hasta el punto que el concepto de «aceña» se identificó y se asoció, desde muy pronto, con la misma instalación del molino pañero. La Partida IIl de la compilación normativa castellana identifica «aceña» con la función de pisar paños, es decir, con el batán asociado a una rueda motriz vertical ${ }^{32}$. A su vez, sabemos que en tiempos de la repoblación valenciana esta tecnología era conocida en ámbito catalán, y que llegó pronto a los espacios hidráulicos valencianos como demuestran numerosos indicios documentales, hasta el punto de poder concluir que la mayoría de los molinos valencianos no harineros eran accionados por ruedas verticales ${ }^{33}$. Estas ruedas suponían prestaciones de tres a cinco veces superiores a la rueda horizontal y, en zonas donde pudieran asociarse a grandes saltos y desniveles, como en estas comarcas del sur, podían incluso incorporarse las de alimentación o impulsión superior, aún más eficientes si cabe ${ }^{34}$. Las descripciones documentales de nuestros molinos del sur asociados a los mismos cursos, construidos sobre estos, sin otros canales propios, parece indicarnos que estamos ante ruedas verticales de impulsión

31. Aún así los conflictos no fueron algo ajeno al uso y funcionamiento de los batanes. Aquí está el origen del citado pleito que generó el molino pañero d'en Ferrada, en la huerta de Valencia, en 1446, que necesitaba ser accionado con dos ruedas porque posiblemente estaba formado por un mayor número de mazas, tal vez cuatro o cinco, y, así, los técnicos que visualizaron el batán indicaron que el dit molí draper no pot obrar ab una roda, com aquell no puixa obrar sino ab molta aygua; y en otra ocasión afirmaron que lo molí draper no pot obrar ab una roda anant, per ço com volentho fer, per lo regolf que fa, llança l'aygua de la cèquia en la cèquia d'en Bonveí appellada, referencias en GLıck, Thomas: Regadío y sociedad..., pp. 112-129.

32. Martínez, María: «Construcción y tipos de molinos..., pp. 409-413; IRAdiel, Paulino, Evolución de la industria textil..., pp. 45-50.

33. Así lo afirman Glick, Thomas \& Martínez, Luis: «La molineria hidràulica..., p. 82.

34. Las ruedas verticales suponen dos tipos: las de alimentación o impulsión inferior y superior. En estas últimas el rendimiento era mayor aunque su puesta en marcha exigía construir presas, juegos de azudes, cauces elevados, etc. REYNOLDS, Terry: «Raíces medievales de la revolución industrial», Investigación y Ciencia, 96 (1984), pp. 98-102; MuNRo, John: «Industrial energy..., pp. 240-263. 
inferior, y así lo confirman las reconstrucciones que se han realizado en la zona sobre batanes en funcionamiento durante los siglos XVIII-XIX ${ }^{35}$. No obstante, algunas citas documentales a desniveles y saltos de agua pronunciados podrían referir al otro tipo de rueda vertical ${ }^{36}$.

Independientemente de una u otra opción, que no siempre podemos determinar, lo que sí resulta evidente es que estamos, en estas comarcas del sur, ante una concentración de esfuerzos tecnológicos, organizativos y de inversión sin precedentes en todo el reino; y que implicó tanto a los poderes feudales como a los artesanos emprendedores cuyo objetivo era el desarrollo de una producción textil de calidad. Pero además, entre ambos grupos, la iniciativa molinar descrita exigía el concurso, la actividad, de muchos otros trabajadores en estos batanes: molineros o pilaters profesionales, con un profundo saber técnico, que conocían bien la máquina y sus partes, y que podían dar solución a cualquier problema técnico; también operarios auxiliares que manejaban los extensos paños, que los movían en sus pilas, que preparaban y aplicaban los productos desengrasantes, que ayudaban a su traslado, etc. Eran aquellos Iog «operarios» que, según el cronista Tomàs Ricord trabajaban en I79I en los 7I batanes valencianos.

\section{LOS BATANES DE COCENTAINA: EJEMPLOS DE PROPIEDAD Y CONTRATACIÓN}

Mientras los batanes ubicados en Ontinyent, Bocairent, Biar, Penàguila o Alcoi formaban parte del patrimonio de la Corona, los cuatro ingenios documentados activos en Cocentina durante el siglo XV, estaban bajo jurisdicción del conde de Cocentaina. Estas diferencias de soberanía no suponían, sin embargo, alteraciones en el sistema de explotación, que en ambos casos se basaban en contratos enfitéuticos a cambio de censos fijos en metálico, modalidad que se fue convirtiendo en la forma básica de gestión de estos monopolios y regalías en buena parte del reino ${ }^{37}$. Es verdad que tales censos diferían enormemente de un molino a otro, y no pueden establecerse parámetros fijos de valor económico, dado que son numerosos los criterios que podían condicionar el canon anual a pagar (ubicación del aparato, estado de su maquinaria y antigüedad, número de mazas, posibles inmuebles o espacios asociados, tiradores, etc.). En la segunda mitad del siglo XV, por fijar una cronología que nos permita comparar, en toda nuestra región batanera algunos artefactos pagaban anualmente 3 sueldos de censo mientras otros llegaban a los 25

35. VIDAL, Vicente: op. cit., pp. 70-86 y Figura 2.

36. Glick duda del tipo de rueda vertical que montaba el molino pañero d'en Ferrada, antes citado, en la huerta de Valencia, ya que los descritos canales de desagüe por los testigos, «indicarían un molino de rueda de impulsión alta», GLICK, Thomas: Regadío y sociedad..., p.129.

37. Viciano, Pau: Els cofres del rei..., pp. 27-43. 
sueldos (computando todos los molinos y sus censos documentados, la media sería de 6 sueldos y 4 dineros $)^{38}$; pero los batanes del conde de Cocentaina satisfacían censos mucho más elevados, de I20 y I40 sueldos anuales (vid. documentos I y 2 del apéndice). Más allá de las posibles diferencias técnicas o estructurales que pudieran determinar estas amplias disparidades, es evidente que tales cifras traslucen el intento, por parte de la autoridad condal, de aprovechar al máximo el inmenso desarrollo de la industria pañera de la villa, de sus centenares de talleres, y de la capacidad económica de su poderoso sector emprendedor local de pelaires y mercaderes de paños que serán los protagonistas de la contratación y gestión de estas instalaciones de alto precio.

Pero, a pesar de estos elevados censos, el interés de los empresarios textiles contestanos no cesaba, al contrario, convertía los batanes en espacios de confluencia de la estrategia y el negocio del capital industrial. Los documentos del apéndice muestran precisamente cómo estos molinos de propiedad condal acaban en manos de esta elite artesanal mediante la compra de su dominio útil, lo que suponía importante inversión económica a largo plazo dado que, junto al pago inmediato de la adquisición, se debía realizar también el del censo anual. Las cifras suponían desembolsos de entre 300 y 700 sueldos, según los ejemplos documentados 39 . En I496 Onofre Navarro (localizado entre I479-I498), uno de los pelaires emprendedores de Cocentaina que conocemos bien por sus múltiples negocios (compra paños crudos que después tinta mediante asociaciones con tintoreros; vende de vino y cereales; arrienda un molino harinero del conde por dos años, y censo de 1.000 sueldos $^{40}$ ) compra el dominio útil de la mitad de un batán en Cocentaina de una sola pila o maza -medietatem mei molendini draper, ... in toto est una pila-, a Joan Figuerola (I479-I502), otro activo pelaire de la villa, distribuidor de lana y también vendedor de paños, que sabemos que adquirió el dominio útil de este batán al conde nueve años antes por un precio total de 600 sueldos que es justo la cantidad por la que ahora vende la mitad de la instalación a su vecino pelaire ${ }^{41}$. La estrategia, y la rentabilidad del negocio, es total, pero lo más interesante no es el beneficio o la amortización que Figuerola consigue en menos de diez años, sino el amplio valor de mercado que un batán tenía en estos momentos de intenso desarrollo de la actividad textil, y que permite deducir

38. Mira documenta los más bien limitados ingresos que todos estos batanes suponían para las arcas de la corona, MIRA, Antonio: «La organización..., pp. 251-271; también VICIANO, Ibídem.

39. Censos elevados se pagaban también en Alzira. En 1385, uno de sus batanes pagaba anualmente 100 sueldos de censo a la corona; en 1407 otro de ellos tenía un censo de 300 sueldos también al patrimonio real (aunque incluía un molino harinero), Martínez Araque, Iván: En els orígens de la indústria rural..., pp. 81-88.

40. Hijo y hermano de pelaires, sabemos que era propietario de, al menos, de cinco parcelas y dos casas en Cocentaina, sobre los detalles proposográficos remitimos al volumen II de nuestra tesis doctoral, LLIBRER, Antoni: Industria textily crecimiento regional. La Vall d'Albaida y el Comtat en el siglo XV (tesis doctoral), Uniersitat de València, vol. II, pp. 213-215.

41. Archivo de Protocolos del Patriarca de Valencia (APPV), $n^{\circ} 23.812$, notario Guillem Peris (1487 enero 16). Gracias al seguimiento prosopográfico conocimos este rentable negocio y otros más de este pelaire, hermano de tintorero e hijo del pelaire Bernat Figuerola, propietario de carnicería y almazara en Cocentiana; Joan es, a su vez, propietario de dos parcelas y una heredad, Ibidem, pp. 132-137. 
una muy elevada revalorización del batán en poco tiempo. De hecho, el valor técnico, estratégico y empresarial del batán es tal, que el propio Figuerola, en el contrato de venta, se reserva la opción de romper el acuerdo y recuperar de nuevo la totalidad del molino (vid. documento). No olvidemos que el vendedor no se desprende del inmueble, en realidad seguirá utilizando el batán, en otra interesante estrategia artesanal mancomunada de gestión: los dos utilizarán el molino, en días o periodos alternos (detalle no especificado en el documento), y pagarán a medias los I2o sueldos anuales de censo enfitéutico al conde. Pero en esa cláusula final el vendedor parece indicar que, ante una posible necesidad de abatanado de paños en su empresa, se reserva el derecho de recuperar la propiedad total de la instalación para su uso exclusivo, devolviendo los 600 o 400 sueldos antes pagados por Navarro ${ }^{42}$.

Parecido contrato encontramos en el documento I. Se trata de nuevo de una venta del dominio directo de otro molino batán, situado en Planes, en la misma comarca del Comtat, a io $\mathrm{km}$ de la capital, realizada en I493. El precio de la transacción aquí es menor al anterior -I26 sueldos- pero su censo enfitéutico anual es algo mayor -I40 sueldos. Sabemos que el hoy vendedor, el pelaire Bartomeu Oltra, accedió al molino trece años antes (en marzo de I480) mediante contrato enfitéutico con el señor de Planes, y con censo idéntico al que ahora aparece en la venta ${ }^{43}$. El precio más ajustado puede estar en relación a la ubicación del batán, alejado de la villa pañera de Cocentaina (localidad del comprador) o a su distinta titularidad. De sus protagonistas destaca el vendedor, Bartomeu Oltra (I469-I493), inicialmente vecino de Planes pero posteriormente habitante en Cocentaina, que es documentado comprando lana y cuero en grandes cantidades, también cereales y aceite (en su familia conocemos la propiedad de una almazara), y que además, en I48I, arrienda el molino harinero de Planes por un año y 800 sueldos ${ }^{44}$.

La inversión que exigía un molino, fuera harinero, pañero o de otra tipología, no debe cuantificarse únicamente por su censo o por el precio de una transacción; se deben tener en cuenta también numerosos gastos asociados a su uso, a su mantenimiento técnico cotidiano, incluso a mayores desembolsos relacionados con los inmuebles. Todo ello hacía interesante la asociación de capitales para la contratación y el acceso a estas instalaciones. Ya hemos visto el caso anterior de la venta de la mitad de un batán, y el documento 3 nos muestra otro ejemplo de esta complementariedad. En este caso vemos cómo el propio conde de Cocentaina, Joan Roís de Corella, realiza en 1502 un arrendamiento a corto plazo de otro de sus molinos: un casal que incluye el aparato para la molienda y el batán (quoddam casale

42. En el contrato se especifica que el comprador pagará inicialmente 400 sueldos, y los 200 restantes en un plazo de dos años. Así Navarro reconoce, en nueva escrituración al final del documento, que adeuda a Figuerola los 200 sueldos pero se compromete a pagarle anualmente un interés de 20 dineros por libra.

43. APPV, $n^{\circ} 23.805$, notario Guillem Peris (1480, marzo 7).

44. Llibrer, Antoni: Industria textil..., vol II, pp. 218-220. 
molendinos fariner et pilater). Por dos años de uso de ambos molinos el conde exige un censo anual de I.320 sueldos. La rentabilidad de la doble instalación parece clara, pero exige una inversión al alcance de pocos arrendatarios. De ahí que sean dos pelaires los que, de forma mancomunada, accedan a tal contrato. Sus prosopografías confirman que estamos, en efecto, ante destacados empresarios del textil: uno es el ya conocido Onofre Navarro, el otro, Pasqual Sempere ${ }^{45}$. Pero ambos destacan por su curricula inversor en la molinería comarcal: en I486 Sempere tomó en arrendamiento un molino harinero del conde por un año y 500 sueldos; y nuestros dos protagonistas -Navarro y Sempere-, también de forma conjunta, arrendaron al mismo conde otro molino harinero (de dos muelas) también por un año, y 800 sueldos. Trece años después encontramos asociados a ambos pelaires para acceder al batán que necesitan sus negocios de producción y acabado de paños; no es casual que los testigos presentes en el momento se materializa el acuerdo sean también destacados operadores del textil: el mercader valenciano Gaspar Rull (que ahora se encuentra en Cocentaina) y el pañero local Miquel Castelló.

La contrastada rentabilidad de los batanes, y sus posibilidades de negocio, permitían estos contratos a corto plazo, de entre uno y dos años, lo que facilitaba la movilidad de estos ingenios entre los pelaires. Así se observa también en otro de estos acuerdos localizados. El último documento que ofrecemos lo protagoniza la viuda del ya citado pelaire Joan Figuerola, que, en I502, cede en arriendo un batán al pelaire vecino Ginés Porta. El contrato supone una duración específica de un año y diez meses, y por un censo de 370 sueldos/año. Las elevadas cantidades llevan a Porta a establecer cuatro plazos de pago que concluirán en diciembre de I504. Pero la cuestión clave aquí es si estamos ante el mismo batán cuya mitad del dominio útil Joan Figuerola vendió a Onofre Navarro en 1496 (aunque todos los indicios documentales nos indican que no). Por un lado, en este nuevo contrato nada se dice sobre su posible titularidad por parte del conde o de otro detentador del dominio directo; nada se indica tampoco de censo enfitéutico alguno; por otro lado, las descripciones físicas de los batanes son diferentes (el primero está en la partida dels molins de senyor, junto al camino real de Penáguila; y el segundo en la partida del río de Alcoi). Todo parece indicar que nos encontramos ante un nuevo batán de propiedad alodial, del que ahora la viuda del pelaire obtendrá rendimiento mediante contratos de arrendamiento a corto plazo y elevado precio. De nuevo vemos el batán como objeto de rédito elevado, un auténtico elemento de lucrativos negocios. Y no se nos debe pasar por alto que un mismo pelaire -Joan Figuerola- pudo acceder a dos batanes, y en un periodo de tiempo muy corto (sólo seis años antes es localizado en el documento anterior), lo que nos indica la capacidad económica e inversora de su empresa textil. El arrendatario

45. Propietario de una heredad, dos parcelas y un taller en Cocentaina, y activo «mercader» de cereales, Ibidem, pp. $279-281$. 
que tendrá este último batán durante los casi dos años del contrato, Ginés Porta, pertenece a una familia con larga tradición local en la pelairía, y de la que hemos documentado hasta cinco profesionales de este sector en la segunda mitad del siglo XV. De Ginés conocemos la propiedad de cuatro parcelas de tierra y dos casas en Cocentaina, pero un dato revelador es que aparece como testigo en una transacción (de compra de cereal) del tundidor vecino Miquel Ferrer, y que ahora, en este arrendamiento del batán, aparece a su vez como testigo de Ginés (el otro testigo es el tendero local Vicent Alçamora) ${ }^{4}$. Tales detalles permiten intuir una posible relación laboral entre pelaire y tundidor, lógica en este caso dado el interés de ambos oficios en el molino pañero, una máquina, una instalación fundamental asociada el desarrollo industrial y a sus estrategias económicas.

\section{EL NEGOCIO DEL BATÁN. A MODO DE CONCLUSIÓN}

El batán se convierte en espacio de convergencia e interés de distintos profesionales, tanto de la producción como de la comercialización; pero también del propio poder feudal que sabe cómo rentabilizar estas instalaciones estratégicas en periodos de crecimiento y alta demanda de una producción textil de calidad. Sólo la conjunción de estos intereses y estos parámetros permite entender el aumento de tales máquinas en un espacio tan limitado y concreto del reino como son las comarcas del sur. La puesta en marcha de casi cuarenta batanes en las primeras décadas del siglo XVI no nace únicamente del interés de la clase feudal, sino de la acción conjunta de diversos sectores artesanales y mercantiles que demandan tal tecnología para su rendimiento industrial, en el mismo periodo que se articulaban los mercados interiores que, a través de una compleja capilaridad, ponían en contacto ciudades, villas y alquerías de toda esta región meridional del país, cuyos consumidores ya no demandaban paños crudos sino abatanados, cardados y tintados.

Ese amplio número de batanes del sur nos dice mucho más, nos habla de un importante desarrollo de la producción pañera. Como recuerda Iradiel, los batanes sólo eran rentables si había abundancia de paños, si su funcionamiento era regular y cotidiano ${ }^{47}$. A su vez, la instalación del batán no sólo venía configurada por su máquina, incluía, como nos indica la documentación, el casal, formado por uno o varios inmuebles para almacenaje de las arcillas y otros productos necesarios en las pilas, incluso con algún espacio para el secado y estirado de los paños una vez realizado el golpeo y tratamiento. Y para todo ello hacía falta una mínima mano de obra, con cierto nivel de especialización y conocimiento tanto de la maquinaria como

46. De Miquel Ferrer (1500-1506) sabemos que es hijo de Bernat y hermano de Pere, ambos tundidores, y miembros de la saga contestana de tundidores Ferrer, de la que hemos documentado cinco profesionales (de 1470 a 1506), que trabajaban para diversos pelaires empresarios de la villa, entre ellos, los Figuerola, Ibidem, pp. 124-127.

47. IRADIEL, Paulino, Evolución de la industria textil..., pp. 46-47. 
del proceso de abatanado y sus productos. El batán movilizaba, pues, tecnología, mano de obra e iniciativa económica.

Podemos así entender cómo únicamente los pelaires más activos y con empresas más solventes accedían a estas instalaciones, que se asociaban a las familias de la elite local. Y hablamos de pelaires porque eran aquí, como hemos visto, los protagonistas de esta tecnología molinar. De forma individual o asociada, eran los que disponían del capital necesario para afrontar sus inversiones; inversiones que exigía, en ocasiones, la misma clase feudal, pero que también sabían aprovechar y gestionar estos artesanos emprendedores. Todo esto daba lugar a la puesta en marcha de mecanismos de explotación y contratación mediante las formas más rentables de arrendamiento a muy corto plazo, que exigían importantes inversiones. Por eso, como hemos analizado en otros trabajos, sin el concurso del capital industrial, proveniente directamente de los mismos pelaires, esta iniciativa manufacturera no se hubiera concretado con esta intensidad. Recordemos que este mismo sector de la pelairía, que ahora financiaba los batanes, era el mismo que, mediante formas similares de ingeniería contractual, gestionaba las tintorerías y el mismo proceso de tintado de los paños, pero también las almazaras, los tiradores y, como hemos visto, muchos de los molinos harineros, numerosas parcelas y hasta heredades o alquerías ${ }^{4}$. También para el acceso a estas instalaciones encontramos arrendamientos, subarrendamientos, ventas del dominio útil, etc.

La inversión molinar era, sin duda, una vía de acción y de actividad de estas empresas textiles que la vieron como necesidad pero también como oportunidad de negocio en un contexto muy determinado de crecimiento manufacturero. Es verdad que tanto el poder feudal como la elite emprendedora de las comunidades artesanales supieron aprovechar las condiciones geográficas favorables en estas comarcas del sur, pero la construcción y el mantenimiento de una densa red de batanes descansaba esencialmente en una producción y una demanda en aumento a lo largo de todo el siglo XV. Un producción pañera que sobrepasaba la elaboración doméstica para el consumo interno, y que trabajaba sus paños -tejiéndolos con lanas de calidad, abatanándolos con las máquinas, cardándolos a la percha y tintándolos de los más diversos colores- con un nivel de especialización laboral y técnica dignos de cualquier ciudad bajomedieval. Y es que, como afirman diversos autores, ningún indicador reflejaba mejor el nivel cuantitativo y cualitativo de la industria textil medieval que el uso y la expansión del batán ${ }^{49}$.

48. Sobre este sector emprendedor de la pelairía, LLIBRER, Antoni: «La formación de compañías para el tintado de paños. El caso de Cocentaina en el siglo XV», Anuario de Estudios Medievales, 41/1 (2011), pp. 59-72; Idem: «Artesanos emprendedores en la industria textil. Del taller al mercado: el caso del pelaire contestano Bernat Martí (1469-1482)», En la España Medieval, 37 (2014), pp. 295-317; Idem: «Llana, ramat i oli. Empreses en època medieval: nivell d'inversió i costos a la draperia (el Comtat al segle XV)», Saitabi, 65 (2015), pp. 63-79; Idem: «Empreses i empresaris en àmbit rural. Sectors i sistemes de gestió. Exemples del País Valencià (segles XV)», en IRADIEL, Paulino et alii: Identidades urbanas Corona de Aragón-Italia (siglos XIV-XV), Univ. de Zaragoza, 2016, pp. 61-74.

49. IRADIEL, Paulino, Evolución de la industria textil..., pp. 46-47; MALANImA, Paolo: I piedi di legno..., pp. 10-16. 


\section{BIBLIOGRAFÍA}

APARICl, Joaquín: El Alto Palancia como polo de desarrollo económico. El sector de la manufactura textil, Ajuntament de Sogorb, 20oI.

APARICl, Joaquín: «Paños, tintes y batanes: mapa de la producción textil medieval en la zona septentrional del Reino de Valencia», Boletín de la Sociedad Castellonense de Cultura, 86 (2010), pp. I85-2I2.

APARICI, Joaquín: «Capilaridad de la manufactura textil en la Plana de Castelló. El caso de Onda en el siglo XV», Anuario de Estudios Medievales, 40-I (2010), pp. I8I-I99

BERnAT, Margalida: «Molins drapers a ciutat de Mallorca: entre interessos polítics i econòmics», Estudis Baleàrics, 58-59 (I987), pp. I27-I50.

Bernat, Margalida: Els «III Mesters de la Llana». Paraires, teixidors de llana i tintorers a Ciutat de Mallorca (s. XIV-XVII), Palma de Mallorca, IEB, I995;

Bernat, Margalida: «Los batanes de Ciutat de Mallorca (siglos XIII-XVII)», en VII Congreso Internacional de Molinología, Zamora, Universidad de Salamanca, 20Io, pp. 406-4I5.

Córdoba, Ricardo: «Aceñas, tahonas y almazaras. Técnicas industriales y procesos productivos del sector agroalimentario en la Córdoba del siglo XV», Hispania, 48/170 (I988), pp. 827-874.

Córdoba, Ricardo: «Los batanes hidráulicos de la cuenca del Guadalquivir a fines de la Edad Media. Explotación y equipamiento técnico», Anuario de Estudios Medievales, 4I/2 (201I), pp. 593-622.

CórdoвA, Ricardo: «Aportaciones de la documentación gráfica y escrita al estudio arqueológico de las instalaciones industriales de época medieval y moderna», en García, Alberto (ed.): Arqueología de la producción en época medieval. Granada, Alhulia, 2013, pp. 43-70.

FERRAGUD, Carmel: El naixement d'una vila rural valenciana. Cocentaina, I245-I304. Valencia, PUV, 2003.

FERRER, Pere et alii: Molins i moliners: molins hidràulics fariners al Comtat, Cocentaina, CEC, 2007.

GLIck, Thomas: Regadío y sociedad en la Valencia medieval. Valencia, Del Cenia al Segura, I988.

GLICK, Thomas \& MARTíNEZ, Luis: «La molineria hidràulica valenciana: qüestions obertes», en Glick, Thomas, Guinot, Enric \& Martínez, Pablo (eds.): Els molins hidràulics valencians. Tecnologia, història i context social. Valencia, Diputació, 2000, pp. 29-99.

HernándeZ, Ricardo: La industria textil en Palencia durante los siglos XVI y XVII. Valladolid, Universidad de Valladolid, 2007.

Hoshino, Hidetoshi: Industria tessile e commercio internazionale nella Firenza del tardo Medioevo. Florencia, 200I.

IRADIEL, Paulino, Evolución de la industria textil castellana en los siglos XIII-XVI. Factores de desarrollo, organización y costes de la producción manufacturera en Cuenca. Salamanca, Univ. Salamanca, I974.

LLIBRER, Antoni: El finestral gòtic. L'església i el poble de Llíria als segles medievals. Valencia, Ajuntament de Llíria, 2003.

Llibrer, Antoni: Los orígenes de la industria de la lana en la baja Edad Media. El Comtat en el siglo XV. Valencia, Generalitat, 2007.

LLIBRER, Antoni: «La formación de compañías para el tintado de paños. El caso de Cocentaina en el siglo XV», Anuario de Estudios Medievales, 4I/I (20II), pp.59-72. 
LLIBRER, Antoni: «La gestió dels batans i el desenvolupament de la indústria tèxtil al segle XV. El cas de l'àrea Alcoi-Cocentaina», Estudis d'Història Agrària, 23 (2012), pp. 23I-248.

Llibrer, Antoni: «La configuració d'un districte industrial a la baixa Edad Mitjana. Les viles draperes de la Vall d'Albaida, l'Alcoià i el Comtat», Recerques: Història, Economia, Cultura, 64 (2013), pp. 5-31.

LLIBRER, Antoni: Industria textil y crecimiento regional: la Vall d'Albaida y el Comtat durante el siglo $X V$. Universitat de València, 2014.

LLIBRER, Antoni: «Artesanos emprendedores en la industria textil. Del taller al mercado: el caso del pelaire contestano Bernat Martí (1469-I482)», En la España Medieval, 37 (20I4), pp. 295-3I7.

Llibrer, Antoni: «Llana, ramat i oli. Empreses en època medieval: nivell d'inversió i costos a la draperia (el Comtat al segle XV)», Saitabi, 65 (2015), pp. 63-79.

LLIBRER, Antoni: «Empreses i empresaris en àmbit rural. Sectors i sistemes de gestió. Exemples del País Valencià (segles XV)», en Iradiel, Paulino et alii: Identidades urbanas Corona de Aragón-Italia (siglos XIV-XV), Univ. de Zaragoza, 20I6, pp. 6I-74.

Malanima, Paolo: I piedi di legno. Una macchina alle origini dell'industria medioevale. Milán, Franco Angeli, I988.

Martínez, María: «Construcción y tipos de molinos hidraúlicos (s. XIII-XV)», Mayurqa, 22 (I989), pp. 40I-4I3.

Martínez, María: «Construcción y tipos de molinos hidráulicos en Murcia (ss. XIII-XV)», Actas del $V$ Congreso de la Sociedad Española de Historia de las Ciencias y de las Técnicas, Murcia, I989, Valera \& López, Carlos (coords.), Murcia, vol. I, I99I, pp. 385-400

Martínez, María: «Desarrollo historiográfico de la molinería hidráulica en la España medieval: perspectivas y resultados», en Galettı, Paola \& Racine, Pierre (coords.) I mulini nell'Europa medievale. Bolonia, Clueb, 2003, pp. I04-I39.

MARTÍNEZ ARAQUE, Iván: En els orígens de la indústria rural. L'artesanat a Alzira i la Ribera en els segles XIII-XV. Valencia, PUV, 2012.

MirA, Antonio: «La organización de la red molinar en la Vall d'Albaida y l'Alcoià a finales de la Edad Media. Infraestructura industrial, desarrollo económico y fiscalidad», en Glick, Thomas, Guinot, Enric \& MarTínez, Pablo (eds.): Els molins hidràulics valencians. Tecnologia, història i context social. Valencia, Diputació, 2000, pp. 229-27I.

Mira, Antonio: Entre la renta y el impuesto. Fiscalidad, finanzas y crecimiento económico en las villas reales del sur valenciano (siglos XIV-XVI).València, PUV, 2005.

MunRo, John: «Industrial energy from water-mills in the European economy, 5 th to I8th Centuries: the limitations of power», Economia e energia, secc. XIII-XVIII. Atti della Settimana di Studi, Prato, Cavacıocchi, Simoneta (ed.), Florecnia, Le Monnier, 2002, pp. 223-269.

PANDuri, Tiziana: «Como Acqua de mola». Mulini ad Acqua nel territorio de Calci in età medievale. Pisa, Università, $200 \mathrm{I}$.

PínTer, Silvia. (I993) «El molí fariner d'Agullent», Almaig. Estudis i Documents, IX, pp. 56-62.

ReYnolds, Terry: «Raíces medievales de la revolución industrial», Investigación y Ciencia, 96 (i984), pp. 98-го2.

SEBAStià, Rafael: «El cauce del río Molinar: vestigio de las primeras fases de la industrialización (Alcoy, Alicante)», Investigaciones geográficas, 24 (2000), pp. I46-I6o.

SElmA, Sergi: «Notes sobre la formació d'uns primers monopolis feudals a la Vall d'Albaida», Alba, 7 (1992), pp. 35-38.

SiCARD, Germain, Aux origines des sociétés anonymes. Les moulins de Toulouse au Moyen Age, Armand Colin, París, I953. 
Torró, Josep: «El molí d’aigua de Descals», Almaig. Estudis i Documents, 6 (I990), pp. 8-I5. TORRó, Josep: (I992) La formación d'un espai feudal. Alcoi, I245-I304. Valencia, IVEI, I992. Viciano, Pau: Els cofres del rei. Rendes i gestors de la batllia de Castelló (I366-1500). Valencia, Afers, 2000.

VIDAL, Vicente: Arquitectura e Industria. Un ensayo tipológico de los edificios fabriles del Alcoià. Valencia, Generalitat, I988. 


\section{APÉNDICE DOCUMENTAL}

\section{Documento 1}

I493, enero i6. Planes (condado de Cocentaina).

Bartomeu Oltra, pelaire vecino de Planes, vende a Gabriel Gilabert, pelaire vecino de Cocentaina, un molino batán, con todos sus instrumentos, situado en Planes. Sobre dicho molino hay un censo de i40 sueldos anuales.

APPV, $\mathrm{n}^{\mathrm{o}} 23.8 \mathrm{r} 6$, notario Guillem Peris, s/f.

Die mercuri intitulata XVI januarii, anno predicto LXXXXIII ${ }^{\circ}$.

Ego Bartholoemus Oltra, panniparator, vicinus ville de Planes, de certa scientia et consulte, cum hoc presenti publico instrumento, vendo vobis Gabrieli Gilabert, panniparator vicino ville Cocentayne, presenti, et vestris, quoddam casale molendinum draper [En margen derecho: cum omnibus suis aparatis et pertrets ad oppus dicti molendini] meum, situm et positum in termino ville de Planes, in partita vulgo dicta $\mathrm{Al}$ Pas de Xàtiva, prout confrontatur cum rivo et cum terris de Planes, quod tenetur facere anno quolibet domino dicte ville de Planes, centum quadraginta solidos regalium Valencie de censu, cum faticha et sine laudimio, anno quolibet solvendorum in die prima mensis januarii. Iamdictum itaque molendinum cum sua roda et omnibus aparatis ad oppus lavorandi dicit molendini, prout ego teneo et posideo, cum ingressibus et egressibus, parietibus, fenestris, rodis et alia necessaria qua ibi sunt, cum omnibus suis iuribus, etc. De quibus, et quibus, etc. Instituhens, etc. Ad habendum, etc. Exceptis, etc. Nisi, etc. Salvo semper dicto domino suo censu. Sich vobis prefato Gabrieli Gilabert presenti et vestris, precio Centum Viginti Sex solidorum regalium Valencie, quas, etc. Unde, etc. Et teneor de firma et legale, etc. Obligo, etc.

Actum in villa de Planes, etc. Et vos teneamini dictum molendinum tenere melioratum et non pignoratum, etc.

Testes huius rei sunt Joannes Vidal et Bartholomeus Thomas, agricole vicini ville de Planes.

\section{Documento 2}

I496, febrero 24. Cocentaina.

Joan Figuerola, pelaire vecino de Cocentaina, vende a Onofre Navarro, también pelaire de dicha villa, la mitad de un molino pañero, con una pila, por un precio de 600 sueldos. Dicho molino tiene como carga un censo de izo sueldos anuales. 
APPV, $n^{\circ}$ 23.8I9, Notario Guillem Peris, s/f.

Die mercuri intitulata XXIIII febroarii, anno LXXXXVI ${ }^{\circ}$.

Ego, Joannes Figuerola, panniparator vicinus ville Cocentayne, de certa scientia et consulte, cum hoc presenti publico instrumento, vendo vobis Onofrio Navarro, panniparatori eiusdem ville vicino, presenti et vestris, medietatem mei molendini draper, situm et positum in termino ville Cocentayne, in partita vulgo dicta dels Molins del senyor de dita vila, prout confrontatur cum camino regali ville de Penaguila et cum alia medietate michi remanenti. In quoquidem molendino in toto est una pila, et totum dictum molendinum facit anno quolibet de censu centum viginti solidos censuales, rendales, perpetuales cum laudimio et faticha, anno quolibet solvendos dominacioni dicte ville in mense aprilis, de quoquidem censu vos teneamini anno quolibet in dicto mense solvere prefato domino dicte ville sexaginta solidos ratione dicte medietatis molendini. Iamdictam itaque medietatem dicti molendini draper prout superius confrontatur, limittatur et terminatur cum introhitibus, exitibus, parietibus, fundamentis a celo in abissum et cum suis roda, pila et aparatibus necessariis cum aqua et cequia et cum omnibus aliis, etc. De quibus, et quibus, etc. Instituhens, ad habendum, etc. Exceptis nisi, salvo dicto nomino, etc. Sich vobis prefato Onofrio Navarro, presenti, et vestris vendo precio Treginta libras ragalium Valencie, quas, etc. Unde renuncio, etc. dans, etc. promittens, etc. Et teneor de firma et legali, etc. fiat executoria, etc. itaque si forte, etc. Obligo, etc. retineo penes me quod quandocumque voluero restituhendo vobis dictas XXX libras vos michi teneamini restituere dictam medietatem molendini sine aliqua tuicione nisi dum tatxat pro factis vestris propiis et dictas XXX libras possum restituhere XX libras in una vice et de alias decem libras respondere [sigue texto ilegible al margen derecho].

Actum Cocentayne, etc. Fiat apoca viginti librarum realiter numerando. Et quia rei veritas. Testes huius rei sunt honorabili Miquael Castello, mercator, et Petrus Despi, carnifex, vicini ville Cocentayne.

Signum nostri Joane Fajardo et de Corella, comitisse Cocentayne, consortis et procuratricis generalis multum spectabilis Joannis Roiç de Corella, comitis Cocentayne, qui receptis viginti unius solidos laudimio dominacioni predicte ville de Cocentayna, pertinenti ratione dicte vendicionis facta gracia de residuis. Igitur eandem vendicionem dicto emptori absenti et suis die XXV supra dictorum mensis et anni in domo alcaceris predicte ville existente; laudavit, concessit et firmavit iure tum dicte dominacioni et suis in rem successoribus semper salvo.

Testes huius rei sunt magnificus Joannes [...], miles, et Garcia Roiç de Mora, habitatores Cocentayne.

Dictis die et anno.

Ego, Onofrius Navarro, panniparator vicinus ville Cocentayne, de certa scientia et consulte, confiteor et in veritate recognosco me debere vobis Joanni Figuerola, panniparatori eiusdem ville vicino, presenti, et vestris, decem libras monete regalium Valencie, et sunt ex resta illarum Treginta librarum dicte monete, pro cuius seu quorum precio a vobis emi quoddam medietatem molendini draper vestri, situm et positum in 
camino dicte ville, cum afrontacionibus et limittationibus, in instrumento vendicionis per notarium infrascriptum recepto, contestis et declaratis. Et quia, etc. Et per pactum specialem inter vos et mee, dictas decem libras, vobis aut cui volueritis, dare et solvere promitto hinc ad tempus duorum annorum primo venturorum, sub pena decem solidorum. Rato, etc. Et interim ratione logerii promitto vobis et vestris respondere interesse ad rationem viginti denariorum pro qualibet libra, anno quolibet in primo die cuiuslibet mensis januarii incipiendo prima die mensis januarii primo venturi, et ex inde annis singulis in dicto die sub pena $V$ solidorum. Rato, etc. Et tamdiu donech dictas decem libras fuerunt solute, omnibus dilacionibus, etc. Ad quorum, etc. Fiat executoria largomodo cum submissione et renunciacione proprii fori et judicii, etc. Obligo, etc.

Actum Cocentayne. Testes huius rei sunt Miquael Castello, mercator, et Petrus Despi, carnifex, vicini ville Cocentayne.

\section{Documento 3}

I502, enero I. Cocentaina.

Onofre Navarro y Pasqual Sempere, pelaires vecinos de Cocentaina, toman en arrendamiento un casal con un molino harinero y otro pañero, propiedad del conde, Joan Roís de Corella, por un período de dos años, y un precio de I.320 sueldos cada año.

\section{APPV, $\mathrm{n}^{\mathrm{o}} 23.823$, Notario Guillem Peris, s/f.}

Die prima mensis januarii, anno predicto $M^{o} D^{o}$ Secundo.

Ego, Joannes Rioç de Corella, habitator ville Cocentayne, scienter et gratis, arrendo ac per viam arrendamenti trado vobis, Onofrio Navarro et Pasquasio Sempere, vicinis ville Cocentayne, presentibus, etc., quoddam casale molendinos fariner et pilater, sitos in rivo dicte ville, ad tempus duorum annorum, de die presenti in antea computandos, pro precio Sexaginta sex librarum regalium Valencie, pro quolibet anno, licet anno quolibet sexaginta sex libras solvendas in tribus equis solucionibus: prima, die prima madii; secunda, die prima septembris; et tercia, ultima dia decembris primo venturos. Et ita per totum dictum tempus duorum annorum, dictum arrendamentum promitto facere, habere et tenere, obligo, etc. Et dicti Onofrius Navarro et Pasquasius Sempere, suscipientes et acceptantes predictum arrendamentum per dictum tempus duorum annorum et pro dicto precio, promitt[imus], simul et insolum vobis et vestris dictas LXVI libras vobis aut cui volueritis anno quolibet solvere in dictis terciis ut suppra, sub pena, pro qualibet solucione, decem solidorum. Rato pacto, etc. Ad quorum omnium, etc. Fiat executoria largomodo cum submissione et renunciacione propii fori et judicii variacione, etc. Obligamus, etc., renunciamus beneficiis dividendorum accionum novarum, etc.

Actum Cocentayne, etc. Testes huius rei sunt magnificus Gaspar Rull, mercator habitator Cocentayne, et honorabilis Michael Castelló, draperius vicinus ville predicte. 


\section{Documento 4}

I502, abril 2I. Cocentaina.

Yolans, viuda de Joan Figuerola, pelaire de Cocentaina, arrienda a Ginés Porta, también pelaire de dicha villa, un molino pañero, situado en Cocentaina, por un período de ocho meses y un año, y un precio de 370 sueldos por año.

APPV, $n^{\circ} 23.823$, Notario Guillem Peris, s/f.

Dictis die et anno.

Ego, Yolans, uxor que fui honorabilis Joannis Figuerola, panniparatoris, vicina ville Cocentayne, de certa scientia, cum hoc presenti publico instrumento, arrendo ac per viam arrendamenti trado vobis, Genesio Porta, panniparatori, eiusdem ville vicino, presenti, et vestris, quoddam molendinum mei pilater, situm et positum in termino ville Cocentayne, [tachado: in] ad latus rivi de Alcoy, ad tempus decem mensium et unum annum, incipiendis decem mensis die prima marcii proxime preteriti, et finient in ultima die decembris de anno $M^{o} D^{o}$ tercio; et dictum annum incipiet die prima mensis januarii de dicto anno $D^{o}$ tercio, et finiet per totum mensem decembris primo venturo de anno a Nativitate Domini $M^{o} D^{o}$ quarto. Pro precio quolibet anno Octodecim librarum decem solidorum regalium Valencie, computandos decem menses ad dictam rationem de octodecim libras decem solidos. Et ita promitto dictum arrendamentum, per totum tempus, facere, habere, tenere, etc. Et teneor, etc. Obligo, etc. Et ego, predictus Genesius Porta, suscipiens et acceptans dictum arrendamentum per dictum tempus et properio de super enarrato, promitto vobis aut cui volueritis, dictum precium anno quolibet solvere hoc modo: per totum mensem augusti primo venturo, decem libras, et per totum mensem decembris, extantem quantitatem ad complementum dictorum decem mensium; et dictum annum promitto solvere novem libras, quinque solidos, in festo Sancti Joannis mensis junii postea subsequenti de anno $M^{o} D^{o}$ tercio; et ultima solucione per totum mensem decembris de anno $M^{o} D^{o}$ quarto, sub pena XX solidorum pro quolibet solucione. Rato, etc. Ad quorum, etc. Fiat executoria cum submissione et renunciacione propii fori et variacione judicii. Obligo, etc. Renuncio, etc. Quodquidem arrendamentum facio iuxta formam usitatam et solitam arrendari, et cum pacto quod si infra dictum tempus in dicta ville sequerenti mors pestilencie, quod Deus avertat, possum relexare dictum molendinum solvendo prorata temporis, vobis et vestris.

Actum in villa Cocentayne die quo suppra. Testes huius rei sunt Michael Ferrer, pannitonsor, et Vicencius Alçamora, tenderius, vicini ville Cocentayne. 
Calidad de Revistas

científicas Españolas

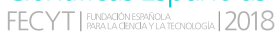

SERIE III HISTORIA MEDIEVAL

REVISTA DE LA FACULTAD DE GEOGRAFİA E HISTORIA
AÑO 2021

ISSN: 0214-9745

E-ISSN 2340-1362

\section{4 \\ issacio. \\ TIEMPO \\ Y FORMA}

\section{Volumen I}

\section{Artículos · Articles}

15 Patricia A. Argüelles Álvarez

Peligros, inseguridades y problemas del viajero visigodo

37 Carmen Barceló, Ana labarta, Josep Benedito \& José M. MELCHOR

Cuatro cerámicas con epigrafía árabe del Museu de Borriana

65 CARlos BARQuero Goñ

Organización de la Orden de San Juan en Castilla durante los siglos XII y XIII

113 Francisco de Paula Cañas Gálvez

Una infanta de Navarra en la corte de Castilla: escenarios políticos en torno a la configuración y evolución del Hostal y la casa de Blanca de Trastámara, Princesa de Asturias (1424-†1464)

\section{David Caramazana Malia}

Las promociones artísticas de Alonso de Ejea, arzobispo y administrador perpetuo de la Archidiócesis de Sevilla y patriarca de Constantinopla (1403-1417)

\section{Pedro Castillo Maldonado}

Privilegios episcopales: la inviolabilidad de los obispos visigóticos y el delito de lesa majestad

\section{MÁxIMO DIAGO HERNANDO}

Alonso de Fonseca, Obispo de Ávila, Cuenca y Osma, y el ascenso de un linaje de exiliados portugueses en la Castilla de los siglos XV y XVI

\section{Antonio PIO dI Cosmo}

Santa Brigida ed il Monte Gargano: un paesaggio dell'anima. La descrizione dell'ambiente come stratagemma d'ammaestramento morale

\section{FERRAN ESQUILACHE}

La 'fila' de agua valenciana y otras medidas de aforo. La verdadera naturaleza de un sistema de medición de caudales de origen andalusí

\section{Alejandro Esteban Álvarez}

Habices del Reino de Granada averiguados en 1528 y 1531: la țā'a nazarí de Órgiva (Alpujarra)

\section{JaVier Gómez Gómez \& IÑAKı MARTín VISO}

Rationes y decimas: evidencias sobre la gestión de las sernas en el siglo XI en el noroeste de la Península Ibérica
383 SANTIAGO GONZÁLEZ SÁNCHEZ

Aportaciones de Paredes de Nava a las campañas militares de Infante Don Fernando, señor de la villa y regente de Castilla, contra el Reino Nazarí de Granada en 1407 y en 1410

429 ANTONI LLIBRER ESCRIG

Una máquina para la industria medieval. Los batanes del sur valenciano: integración y negocio. Nuevas aportaciones (1490-1502)

455 José Miguel López Villalba Comunicación escrita y oral de la ordenanza municipa (siglos XV-XVI)

501 Emilio Martín Gutiérrez

El aprovechamiento de los recursos naturales: la grana en Andalucía occidental durante el siglo XV

\section{Volumen II}

537 VERA-CRuz Miranda MENACHO

$(1421-1461)$

Las finanzas de un heredero: Carlos de Aragón y Navarra

569 Raúl Morales Muñoz

Hacia una revalorización del conciliarismo hispano bajomedieval: el Defensorium Trium Conclusionum de Alfonso de Madrigal

605 David Nogales Rincón

Enrique III de Castilla (1390-1406) y la indagación de rentas: un proyecto regio para la búsqueda de mineros y tesoros a inicios de cuatrocientos

6.7.7 Gonzalo Oliva Manso

Seisenes y novenes. Tiempos de calma para la moneda castellano-leonesa (1282-1312)

685 Alberto Peña Fernández y Manuel García Alonso Una inscripción medieval inédita en la iglesia de San Miguel de Aguayo (Cantabria)

713 RODRIGO POUSA DIÉGUEZ

Configuración institucional de una villa costera: Muros en el tránsito de la Edad Media a la Edad Moderna

\subsection{JuAn A. Prieto Sayagués}

Las profesiones femeninas de la nobleza y de las oligarquías urbanas en la Castilla bajomedieval. Causas, dinámicas, privilegios y donaciones 


\section{4}

\section{ESPACIO,}

\section{TIEMPO}

Y FORMA

UกED

SERIE III HISTORIA MEDIEVAL

REVISTA DE LA FACULTAD DE GEOGRAFÍA E HISTORIA

815 María del Pilar Rábade Obradó

El miedo a la Inquisición en la Castilla de los Reyes Católicos

84.5 Carlos Manuel Reglero de la Fuente

EL abad contra el rey (y los regidores): conflicto de jurisdicciones y ejercicio del poder en Sahagún (1398-1417)

881 Manuel Alejandro Rodríguez de la Peña

Eusebius and Alcuin on Constantine and Charlemagne as Wise Rulers: Sapiential Rulership in Late Antiquity and the Early Middle Ages

9)15 Antonio SÁnCHEZ GonzÁlez

El Archivo de los Mariscales de Castilla y Marqueses de Malagón

\section{Estudios y comentarios}

9. 51 Serafín Olcoz Yanguas

Apostilla al estudio Influencia de las redes nobiliarias en la expansión cristiana del siglo XII: el caso de Soria (ETF, 33, 2020)

\section{Libros · Books}

969 CAstrillo CASAdo, Janire, Las mujeres vascas durante la Baja Edad Media (MARía Jesús Fuente)

973 Crónica del rey Juan II de Castilla. Minoría y primeros años de reinado (1406-1420) GARCIA, Michel (edición y estudio) (VÍctor MUÑ̃z GómEZ)

981 DA Silva, Marcelo Cândido, História Medieval (DIEgo CARLo AMÉNDOLLA SPÍNOLA)

9.87 Galende Díaz, Juan Carlos y Ávila SeoAne, Nicolás, El rodado regio hispánico. Fernando III de León y Castilla (12301252) (MAURICIO HERRERO JIMÉNEZ)

989 García IzQuierdo, Iván, Frontera, fuero y concejos. EI valle del Riaza en la Edad Media (siglos VIII-XII) (CARLOS BARQUERO GOÑI)

993 García IzQuierdo, Iván y Peterson, David (coords.), Camino y Señorío. Obra selecta de Luis Martínez García (ENRIQUe CANTERA MONTENEgRO)

995 GonzÁlez PAz, Carlos Andrés, O Bispado de Mondoñedo na Idade Media. Territorio, comunidade e poder (ENRIQUE CANTERA Montenegro) 


\section{4}

\section{ESPACIO,}

\section{TIEMPO}

Y FORMA

UกED

SERIE III HISTORIA MEDIEVAL

REVISTA DE LA FACULTAD DE GEOGRAFİA E HISTORIA

\section{Libros · Books}

9) López MARtínez, Amalia, Minutarios notariales de Estevo Pérez (Ourense, siglo XIV) (José MIgUel LóPEz VILLALBA)

999 Miranda García, Fermín y López de Guereño SAnz, María Teresa (eds.), La muerte de los príncipes en la Edad Media. Balance y perspectivas historiográficas (ANA ECHEVARRÍA ARSUAGA)

1003 Motis Dolader, Miguel Ángel, Vivencias, emocionesy perfiles femeninos. Judeoconversas e Inquisición en Aragón en el siglo XV (ANA ECHEVARría ARsuaga)

1007 Solórzano Telechea, Jesús Ángel y Martín PÉrez, Fernando (coords.), Rutas de comunicación marítima y terrestre en los reinos hispánicos durante la Baja Edad Media. Movilidad, conectividad y gobernanza (ENRIQUE JOSÉ RUIZ PILARES)

1013 TORRE, Sandra de la - ETXEBERRIA, Ekaitz - DíAz DE DURANA, José Ramón (coords.), Valer más en la tierra. Poder, violencia y linaje en el País Vasco bajomedieval (ENRIQUE CANTERA MONTENEGRO)

1015 TRILlo SAN José, Carmen, La Vega de Granada a partir de documentación árabe romanceada inédita (1457-1494). Estudio, edición e índices (INMACULADA GONZÁLEZ SOPEÑA)

1019 Val Valdivieso, M. ${ }^{a}$ Isabel - VillanueVa ZubizarReta, Olatz (Coords.), Pero Ansúrez. El conde, su época y su memoria (ENRIQUe CANTERA MONTENEGRO)

1021 Villanueva Morte, Concepción y Fernández de Córdova Miralles, Álvaro, El embajador Claver. Diplomacia y conflicto en las «Guerras de Italia» (1495-1504) (ENRIQUE Cantera Montenegro) 